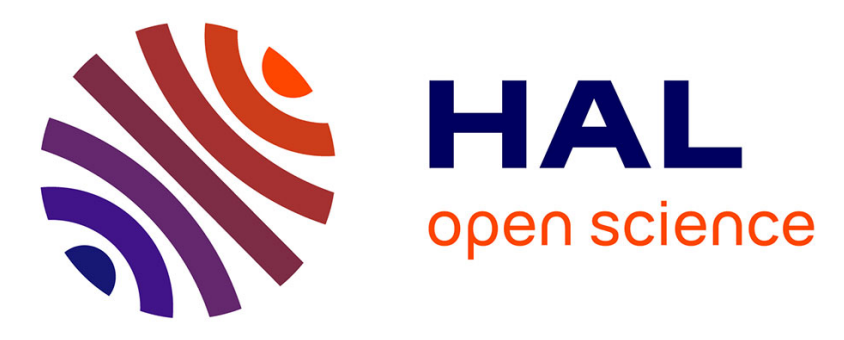

\title{
Phosphate adsorption on $\gamma$-alumina: a surface complex model based on surface characterization and zeta potential measurements
}

Teddy Roy, Dorothea Wisser, Mickaël Rivallan, Manuel Corral Valero, Thibaut Corre, Olivier Delpoux, Gerhard D. Pirngruber, Grégory Lefèvre

\section{To cite this version:}

Teddy Roy, Dorothea Wisser, Mickaël Rivallan, Manuel Corral Valero, Thibaut Corre, et al.. Phosphate adsorption on $\gamma$-alumina: a surface complex model based on surface characterization and zeta potential measurements. Journal of Physical Chemistry C, 2021, 125 (20), pp.10909-10918. 10.1021/acs.jpcc.0c11553 . hal-03379556

\section{HAL Id: hal-03379556 https://hal.science/hal-03379556}

Submitted on 15 Oct 2021

HAL is a multi-disciplinary open access archive for the deposit and dissemination of scientific research documents, whether they are published or not. The documents may come from teaching and research institutions in France or abroad, or from public or private research centers.
L'archive ouverte pluridisciplinaire HAL, est destinée au dépôt et à la diffusion de documents scientifiques de niveau recherche, publiés ou non, émanant des établissements d'enseignement et de recherche français ou étrangers, des laboratoires publics ou privés. 


\title{
Phosphate adsorption on $\boldsymbol{\gamma}$-alumina: a surface complex model based
}

\section{on surface characterization and zeta potential measurements}

Teddy Roy ${ }^{\mathrm{a}}$, Dorothea Wisser ${ }^{\mathrm{a}}$, Mickaël Rivallan ${ }^{\mathrm{a}}$, Manuel Corral Valero ${ }^{\mathrm{a}}$, Thibaut Corre ${ }^{\mathrm{a}}$, Olivier Delpoux ${ }^{\mathrm{a}}$, Gerhard D. Pirngruber ${ }^{\mathrm{a}}$, Grégory Lefèvre ${ }^{\mathrm{b}^{*}}$

${ }^{a}$ IFP Energies nouvelles, Direction Catalyse et Séparation, Rond-point de l'échangeur de Solaize, 69360 Solaize, France

${ }^{\mathrm{b}}$ Chimie ParisTech, PSL Research University, CNRS, Institut de Recherche de Chimie Paris (IRCP), F75005 Paris, France

*Corresponding author e-mail and phone number:

gregory.lefevre@chimieparistech.psl.eu / +33 (0)1 85784268

\begin{abstract}
An innovative approach using solid/liquid interface characterization (zetametry measurements, ATR-IR), coupled with ex situ FTIR has been used to build a phosphate complexation model at the alumina surface via the PHREEQC software. According to the phosphorus coverage impregnated on the alumina surface, two mechanisms of adsorption have been identified: a specific surface complex adsorbed on the predominant alumina facet and a surface precipitation process. At low phosphorus coverage ( $\mathrm{P}$ coverage $\left.<1.2 \mathrm{at} / \mathrm{nm}^{2}\right)$, the adsorption proceeds mainly through a monodentate complex adsorbed on $\mu_{1}-\mathrm{Al}_{\mathrm{IV}}-\mathrm{OH}$ sites located on the (110) facet, a bidentate involving $\mu_{1}-\mathrm{Al}_{\mathrm{V}}-\mathrm{OH}(110)$ is also discussed. However, the surface concentration of these particular sites is limited. Thus, above the threshold of $1.2 \mathrm{at} / \mathrm{nm}^{2}$, a surface precipitation occurs with the formation of an amorphous $\mathrm{AlPO}_{4}$ phase, experimentally observed by FTIR and zetametry measurements.
\end{abstract}

\section{Introduction}

$\mathrm{V}-\mathrm{Al}_{2} \mathrm{O}_{3}$ is an oxide of major importance in both industrial and environmental fields. $\mathrm{Y}-\mathrm{Al}_{2} \mathrm{O}_{3}$ is involved in numerous catalytic processes as an active catalyst (Claus Process) but mainly as a catalytic support in petroleum refining, cleaner fuel production from fossil and biomass resources (hydrotreatment field) or in exhaust gas catalytic converters.

In the large number of applications or systems mentioned, phosphorus appears to be a key element. It could enter in the composition of heterogeneous catalysts used in different processes linked to fuel or energy production and storage (hydrotreatment ${ }^{1}$, biomass transformation ${ }^{2}$, zinc-air battery ${ }^{3}, \ldots$..). Thus, by modifying the support acidity or the interaction between the active phase precursors and the support of heterogeneous catalyst, phosphorus helps to enhance the catalytic activity. For 
instance, in the case of hydrotreatment, phosphorus can lead to a better dispersion of the active phase $^{4}$, to less deactivation ${ }^{5}$, to a lower amount of inactive promoter species ${ }^{6}$, and to the formation of a more easily reducible active phase ${ }^{7}$. The determination of the interaction between phosphate and the catalyst's support is a great concern to understand its impact on the catalytic performance and design better catalysts.

Consequently, understanding phosphate interaction with oxides surfaces at the solid/liquid interface (support/impregnation solution) is of great interest. The interface is usually described by the Triple Layer model. The first layer situated between the surface and the Inner Helmholtz plane (IHP) contains the ions adsorbed specifically onto the surface mainly by covalent bonding. The second one situated between the IHP and the Outer Helmholtz plane (OHP) is composed by ions retained by electrostatic adsorption or hydrogen bonding. The last region, beyond the OHP is called the diffuse layer and is mainly composed by counter-ions. In order to study their interaction and their surface speciation, three methodologies are mainly used in the literature. Two mainly experimental techniques have been applied in order to describe the adsorption mechanisms. On the one hand, spectroscopic studies were performed to determine the geometry of the adsorbed surface complex at a molecular scale, mainly using infrared spectroscopy ${ }^{8-10}, \mathrm{X}$-ray absorption spectroscopies as XANES $^{11}$ or more recently solid state Nuclear Magnetic Resonance (NMR) ${ }^{12}$. On the other hand, macroscopic studies (adsorption isotherms, electrokinetic measurements, $\mathrm{pH}$ edges, ...) ${ }^{1,13}$ were used to build surface complexation models consistent with adsorption equilibria. The last approach concerns the development of Density Functional Theory (DFT) models and calculations which help to gain information on surface ${ }^{14}$ and stability of adsorbed species, and lead to build more accurate ${ }^{15}$ surface complexation models.

The usefulness of the combination of these three approaches is well illustrated by the determination of the phosphate adsorption mode onto an iron oxyhydroxide, goethite. Indeed, first using thermodynamic and spectroscopic data, Parfitt et al. ${ }^{16}$ interpreted the phosphate adsorption on synthetic goethite by a bidentate bridging complex, while Tejedor-Tejedor et al. ${ }^{17}$ used both bidentate and monodentate complexes. These first assumptions on the adsorption modes were in contradiction with the work of Persson et al. ${ }^{18}$ who used spectroscopic information, complex symmetry and thermodynamic data to explain the adsorption by a monodentate complex with three degrees of protonation along the $\mathrm{pH}$ changes. Finally, the studies were reconciled using spectroscopic experiments (IR, XANES), DFT calculation and surface complexation modelling to indicate the presence of both mono and bidentate species with different degrees of protonation ${ }^{19}$. A DFT study went even further and explained the presence of both bi/monodentate inner sphere complex and outer sphere complex depending on the $\mathrm{pH}$ as well as on the face exposed by goethite particles ${ }^{15}$.

This approach combining spectroscopic, macroscopic and theoretical studies proved to be efficient for iron (hydr)oxides and especially for goethite. Nevertheless, regarding $\gamma-\mathrm{Al}_{2} \mathrm{O}_{3}$, the determination of the adsorption mode is not straightforward, due to the heterogeneity of the poorly crystalline $\gamma^{-}$ $\mathrm{Al}_{2} \mathrm{O}_{3}$ surface, the possible hydration reaction at the solid/solution interface and the partial overlap of infrared signals between alumina and adsorbed phosphate. Several studies have been performed at macroscopic level including adsorption isotherms and electrokinetic measurements ${ }^{13,20,21}$ to study the adsorption capacity of aluminum (hydr)oxides towards phosphate reporting the strong influence of the impregnation $\mathrm{pH}$ and phosphorus coverage. Other authors using mainly spectroscopic 
information proposed different adsorption modes and phosphate complex geometry: Zheng et al. ${ }^{8}$ using ATR-IR in situ and Li et al. ${ }^{12}$ by NMR have concluded on the presence of bidentate binuclear complex without ruling out the presence of monodentate species with different degrees of protonation. Recently, considerable progress has been made with DFT calculations ${ }^{14,22}$ to describe the surface as well as DFT-based $a b$ initio molecular dynamics (AIMD) simulation ${ }^{23,24}$ and MUSIC model $^{25}$ to perform speciation calculations of surface sites at the solid/solution interface.

Nevertheless, no consensus appears in the literature on the inner-sphere complex geometry, denticity or protonation state of phosphate adsorbates on $\mathrm{y}-\mathrm{Al}_{2} \mathrm{O}_{3}$, whereas phosphate adsorption clearly leads to an important surface modification.

In this study, a multi-technique approach has been developed in order to improve the description of the adsorbed phosphate species onto the $\mathrm{\gamma}-\mathrm{Al}_{2} \mathrm{O}_{3}$ surface by describing the complex geometry as well as the adsorption sites at the surface. Dried samples are prepared by incipient wetness impregnation at different phosphorus coverage (from 0.5 to $4.5 \mathrm{at} / \mathrm{nm}^{2}$ ) to study its impact on the surface speciation. FTIR and ATR-IR spectroscopic measurements have been performed to probe both phosphate surface complexes and hydroxyl surface sites involved at both hydrated and dehydrated surface state. On the basis of zetametry measurements, a surface complexation model at solid/liquid interface involving a DFT description of the alumina surface combined with MUSIC model has been built to include the complex denticity, protonation state and the adsorption sites at the $\mathrm{\gamma}-\mathrm{Al}_{2} \mathrm{O}_{3}$ surface.

\section{Experimental Section}

\section{Sample preparation by incipient wetness impregnation}

All samples were prepared by aqueous incipient wetness impregnation technique ${ }^{26}$. Boehmite Pural SB3 (purchased from Sasol) calcined under vacuum at $540^{\circ} \mathrm{C}$ for 4 hours with extrudate shape was used as a support. These extrudates were crushed to obtain particles between 400 and $800 \mu \mathrm{m}$ in order to avoid diffusion limitation. The support had a surface area of $209 \mathrm{~m}^{2} \mathrm{~g}^{-1}$ and a pore volume of $0.88 \mathrm{~cm}^{3} \mathrm{~g}^{-1}$ determined by nitrogen physisorption and mercury porosimetry. Phosphoric acid ( 85 $w t \%)$ and ammonia ( $28 \mathrm{wt} \%$ ) (from Alfa Aesar) were used as starting chemicals. All products were used as received. The starting $\mathrm{pH}$ of the phosphoric acid impregnating solution was adjusted to 4 by ammonia. $\mathrm{P} / \mathrm{Al}_{2} \mathrm{O}_{3}$ samples showed in Table 1 were prepared by impregnation followed by a maturation step under saturated water vapour atmosphere for 16 hours and a drying stage at $120^{\circ} \mathrm{C}$ for 6 hours. The phosphorus loadings were determined by X-ray fluorescence (XRF) spectroscopy (Table 1).

Table 1 : Phosphorus on alumina samples of the study

\begin{tabular}{cccccccc}
\hline Sample name & $\mathrm{Al}_{2} \mathrm{O}_{3}$ & $\begin{array}{c}\mathbf{0 . 5} \\
\mathrm{at} / \mathbf{n m}^{2}\end{array}$ & $\begin{array}{c}\mathbf{1} \\
\mathrm{at} / \mathrm{nm}^{2}\end{array}$ & $\begin{array}{c}\mathbf{1 . 3} \\
\mathrm{at} / \mathbf{n m}^{2}\end{array}$ & $\begin{array}{c}\mathbf{1 . 8} \\
\mathrm{at} / \mathbf{n m}^{2}\end{array}$ & $\begin{array}{c}\mathbf{3} \\
\mathrm{at} / \mathbf{n m}^{2}\end{array}$ & $\begin{array}{c}\mathbf{4 . 5} \\
\mathbf{a t} / \mathbf{n m}^{2}\end{array}$ \\
\hline $\begin{array}{c}\text { Targeted } \mathrm{P} \\
\text { coverage }\left(\mathrm{at} / \mathrm{nm}^{2}\right)\end{array}$ & 0 & 0.5 & 1 & 1.3 & 1.8 & 3 & 4.5 \\
$\begin{array}{c}\mathrm{P} \text { coverage XRF } \\
\left(\mathrm{at} / \mathrm{nm}^{2}\right)\end{array}$ & 0.0 & 0.4 & 1.1 & 1.4 & 1.6 & 2.9 & 4.6 \\
\hline
\end{tabular}


$\mathrm{AlPO}_{4}$ was prepared from aqueous solutions of aluminum salt $\left(\mathrm{Al}\left(\mathrm{NO}_{3}\right)_{3} .9 \mathrm{H}_{2} \mathrm{O}\right.$, Carlo Erba reagent) and $\mathrm{H}_{3} \mathrm{PO}_{4}$ (85 wt\% from VWR chemicals) by precipitation at room temperature with aqueous solution of ammonia $(1 \mathrm{M})$. A solution containing a molar ratio Al/P of 2 was continuously stirred while $\mathrm{NH}_{3}$ was dropwise added until a white gel precipitated and the $\mathrm{pH}$ of the supernatant reached 4.5. After filtration, the gel has been washed twice with distilled water and dried at $120^{\circ} \mathrm{C}$ for 16 hours. Transmission FTIR Spectroscopy

The FTIR spectra were collected using a Vertex 70 spectrometer in the $4000-400 \mathrm{~cm}^{-1}$ range. Spectral resolution was $4 \mathrm{~cm}^{-1}$ and spectra were averaged with 32 scans. The samples were activated at room temperature or $450^{\circ} \mathrm{C}$ under high vacuum $\left(<10^{-5} \mathrm{mbar}\right)$. The powdered samples of approximately 20 $\mathrm{mg}$ were pressed into self-supporting pellets of $16 \mathrm{~mm}$ in diameter. Data processing was carried out using OMNIC and Origin software.

\section{ATR-IR Spectroscopy}

The ATR-IR spectra were collected in the range $4000-650 \mathrm{~cm}^{-1}$ with a dry-air-purged Thermo Scientific Nicolet IS50 FT-IR equipped with a MCT-B detector. Spectral resolution was $4 \mathrm{~cm}^{-1}$ and spectra were averaged from 256 scans. The crystal used was a single reflection diamond/ZnSe crystal. The angle of incidence is $45^{\circ} \mathrm{C}$ (Smart PIKE). In order to maximize the contact between the sample and the crystal, the sample was crushed to powder before deposition on the crystal and then pressed onto the crystal during the analysis. Data processing was carried out using OMNIC software. All spectra were retreated using the same procedure: atmospheric correction, an advanced ATR correction and auto baseline correction between 900 and $1700 \mathrm{~cm}^{-1}$.

The in situ ATR-IR spectra were collected with the same dry-air-purged Thermo Scientific Nicolet IS50 FT-IR, equipped with a MCT-B detector. Spectral resolution was $4 \mathrm{~cm}^{-1}$ and spectra were averaged from 256 scans. The horizontal diamond/ZnSe crystal was coated with $1 \mu \mathrm{L}$ of a $\gamma-\mathrm{Al}_{2} \mathrm{O}_{3}$ suspension ( 1 $\mathrm{g} \mathrm{L}^{-1}$ ) which was dried under a flow of $\mathrm{N}_{2}$. This procedure was repeated twice. A flow cell was clamped on the ATR accessory and a background was recorded. In order to stabilize the coating, distilled water adjusted at $\mathrm{pH} 4$ with $\mathrm{HNO}_{3}(1 \mathrm{M})$ was flushed on the oxide film with a constant flow rate of $1 \mathrm{~mL} \mathrm{~min}{ }^{-1}$ using a peristaltic pump (Ismatec S.A.) at room temperature. After 30 minutes of stabilization of the coating observed by the absence of difference between two consecutive spectra, the background spectrum was recorded and a phosphate solution adjusted at $\mathrm{pH} 4$ was used as the circulating solution. For data processing, OMNIC software was used.

\section{Zetametry}

The zeta potential measurements were performed using a Malvern Nano ZS Zetasizer. Zeta potentials were calculated from measured electrophoretic velocity rates using the Smoluchowski equation. Measurements were carried out using $100 \mathrm{mg}$ of powdered samples suspended in $100 \mathrm{~mL}$ of aqueous solutions under stirring. The $\mathrm{pH}$ of the suspension was adjusted with $0.1 \mathrm{M} \mathrm{HNO}_{3}$ and $0.1 \mathrm{M}$ (or $0.01 \mathrm{M}$ ) $\mathrm{NaOH}$ solutions prepared from VWR commercial solution. The starting $\mathrm{pH}$ was adjusted around 3. After a few minutes of equilibration, an aliquot was withdrawn and analysed using the Zetasizer. It was then poured back in the reactor. After the $\mathrm{pH}$ adjustment with $\mathrm{NaOH}$, a new aliquot was withdrawn when the $\mathrm{pH}$ value was stable. The protocol was repeated until $\mathrm{pH}$ reached a value of approximately 10. These measurements were also used to obtain the isoelectric point (IEP, i.e. the $\mathrm{pH}$ value at which $\zeta=0 \mathrm{~V}$ ). 


\section{PHREEQC Modelling}

PHREEQC2 speciation software was used to model the variation of the samples IEP with increasing $P$ loading. The acido-basic equilibria at the alumina surface determined by Corral Valero et al. ${ }^{25}$ have been used. The electrostatic model was the basic Stern model and the capacitance $C_{1}$ selected is 1.39 $\mathrm{F} / \mathrm{m}^{2}$, as used by Mayordormo et $a .^{27}$ to model the bidentate adsorption of selenium ion on alumina surface.

Experimentally, the IEP is determined by taking the $\mathrm{pH}$ value at which the zeta potential is zero. Its value cannot be determined directly in surface speciation calculations, since only the value of the potential at the Stern plane $\left(\psi_{1}\right)$ is calculated in this approach while the shear plane, measured in zeta potential measurements, is located further away in the diffuse layer ${ }^{28}$. Nevertheless, Stern and shear plane potentials coincide when their value is close to zero. Thus, the theoretical IEP has been determined as the $\mathrm{pH}$ where $\psi_{1}$ is equal to zero.

The modelling has been performed on phosphate-treated $\mathrm{\gamma}-\mathrm{Al}_{2} \mathrm{O}_{3}$. It has been observed that once sorbed, the phosphate species are not released in solution, i.e. the adsorption equilibrium does not take place after rehydration of the surface. Thus, the sorption equilibrium have not been implemented in PHREEQC code, as usually done in model solid/solution reactions. The protocol which has been developed was to replace in the description of the surface a given fraction of hydroxyl sites by a surface complex, following the stoichiometry of the assumed adsorption reaction and the surface density of adsorbed phosphate.

The surface precipitation of $\mathrm{AlPO}_{4}$ has been implemented by replacing a given fraction of hydroxyl surface groups by a surface site with a pKa equal to the IEP of this compound, determined experimentally, following 1-pK approach ${ }^{29}$.

\section{Results and discussion}

\section{Characterization of the surface}

$\mathrm{Y}-\mathrm{Al}_{2} \mathrm{O}_{3}$ presents a large variety of surface hydroxyl groups which differ from the number of aluminum atoms they are bounded to, the coordination number of the(se) latter(s) and the surface orientations of $\gamma$-alumina. Indeed, surface hydroxyls are distributed along the $\gamma$-alumina planes (110), (100) and (111). However, according to Beaufils and Barbaux ${ }^{30}$, the surfaces (110) and (100) represent more than $90 \%$ of the specific surface area, which has led Digne et al. ${ }^{14}$ to develop a model in which the (100) and (110) orientations account for 20 and $80 \%$ of the specific area, respectively. The diversity of surface hydroxyls has been detailed in the model developed by Digne ${ }^{22}$ which is summed up in the Table 2 where the different $\mathrm{OH}$ types are associated to its experimental and calculated infrared signals on the three alumina planes. 
Table 2 : Overview of assignment of $\mathrm{OH}$ bands in FTIR spectra of surface hydroxyls and P-OH groups. $\mu_{1}$ : terminal $\mathrm{OH}$ and $\mu_{2}$ : bridging $\mathrm{OH}^{14}$.

\begin{tabular}{|c|c|c|c|c|}
\hline Site & Surface & $\mathbf{v}_{\text {cal }}^{22}\left(\mathrm{~cm}^{-1}\right)$ & $v_{\text {exp }}\left(\mathrm{cm}^{-1}\right)$ & $\begin{array}{c}\text { Qualitative evolution } \\
\text { with increase P } \\
\text { coverage }\end{array}$ \\
\hline$\mu_{1}-\mathrm{Al}_{\mathrm{IV}}-\mathrm{OH}$ & $(110)$ & 3842 & 3794 & $\pi$ \\
\hline$\mu_{1}-\mathrm{Al}_{\mathrm{VI}}-\mathrm{OH}$ & $(100)$ & 3777 & 3770 & $y$ \\
\hline$\mu_{3}-\mathrm{Al}_{\mathrm{V} 1}-\mathrm{OH}$ & (111) & 3752 & 3752 & $y$ \\
\hline$\mu_{1}-\mathrm{Al}_{V}-\mathrm{OH}$ & $(110)$ & 3736 & 3730 & $\searrow$ \\
\hline$\mu_{2}-\mathrm{Al}_{\mathrm{V}}-\mathrm{OH}$ & $(110)$ & 3707 & 3690 & $\approx$ or $\searrow$ \\
\hline $\mathrm{P}-\mathrm{OH}$ & / & 1 & 3680 & $\lambda$ and $=$ \\
\hline$\mu_{2}-\mathrm{Al}_{\mathrm{VI}}-\mathrm{OH}$ & (111) & 3690 & 3670 & $\searrow$ \\
\hline$\mu_{2}-\mathrm{Al}_{\mathrm{VI}}-\mathrm{OH}$ & $(110)$ & 3641 & 3630 & 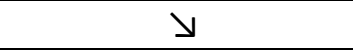 \\
\hline $\begin{array}{c}\mu_{3}-\mathrm{Al}_{\mathrm{V}}-\mathrm{OH} \text { or } \mathrm{H}- \\
\text { bond network }\end{array}$ & $(100)$ & 3589 & 3580 & $\searrow$ \\
\hline
\end{tabular}

\section{Transmission Infrared Spectroscopy (FTIR)}

The spectra of dried samples have been recorded for phosphorus coverage from 0 to $4.5 \mathrm{at} / \mathrm{nm}^{2}$ after an activation at room temperature under vacuum $\left(<10^{-5} \mathrm{mbar}\right)$ (Figure 1.A). By the room temperature pretreatment, we aimed to remove only physisorbed water so as to make the vibrations of surface hydroxyl groups visible, without modifying the surface speciation. The H-bonding of the surface hydroxyl groups with residual water leads to large and poorly resolved bands. That is why we also recorded spectra after dehydration at $450^{\circ} \mathrm{C}$ (Figure 1.B). The general tendency of the bands' evolution with $\mathrm{P}$ coverage is conserved in Figure 1.A and $\mathrm{B}$, but the trends discussed below are more visible in the spectra after dehydration at $450^{\circ} \mathrm{C}$.

Spectra present up to nine bands at 3794, 3770, 3755, 3730, 3690, 3680, 3670, 3640 and $3580 \mathrm{~cm}^{-1}$, and most of them can be attributed to the surface $\mathrm{OH}$ groups from the model developed by Digne et $a l^{22}$ as summed up in Table 2.
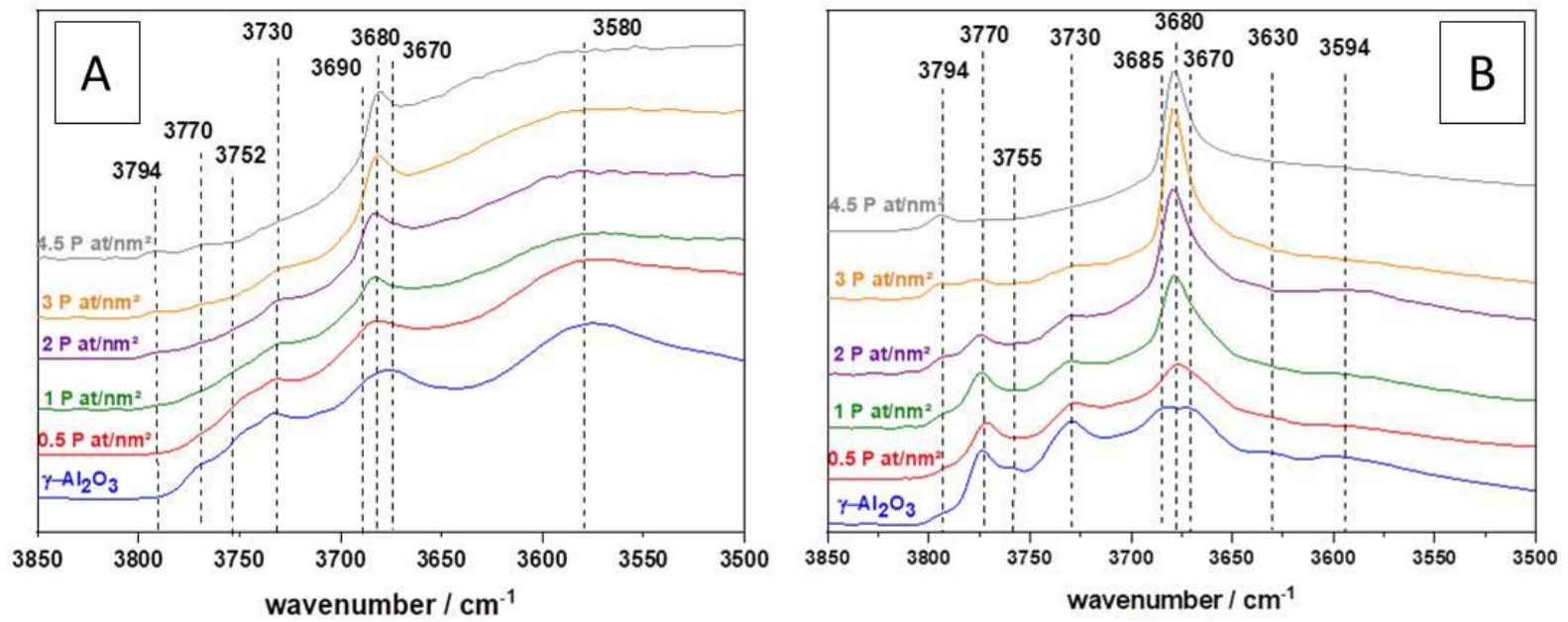

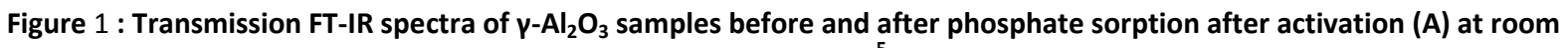
temperature or $(\mathrm{B}) 450^{\circ} \mathrm{C}$ under vacuum $\left(10^{-5} \mathrm{mbar}\right), \mathrm{OH}$ stretching region. 
Bands at $3770, \sim 3755$ and $3730 \mathrm{~cm}^{-1}$ are assigned to $\mu_{1}-\mathrm{Al} \mathrm{V}_{\mathrm{V}}-\mathrm{OH}(100), \mu_{3}-\mathrm{Al}_{\mathrm{VI}}-\mathrm{OH}(111), \mu_{1}-\mathrm{Al}_{\mathrm{V}}-\mathrm{OH}$ (110), respectively. The broad band at $3580 \mathrm{~cm}^{-1}$ in the room temperature spectrum can be attributed to an $\mathrm{H}$-bonding network ${ }^{22}$. All these bands become weaker with phosphate loading (see also the difference spectra in the supporting information, Figure S1) and thus seem to be consumed by the phosphorus adsorption. Upon phosphate adsorption, only two bands increase with the phosphorus coverage, i.e. the $3680 \mathrm{~cm}^{-1}$ and the $3794 \mathrm{~cm}^{-1}$ bands (discussed later). The band at 3680 $\mathrm{cm}^{-1}$ progressively grows as function of $\mathrm{P}$ coverage and is ascribed to the formation of $\mathrm{P}-\mathrm{OH}$ groups. Note that a band of bare alumina, attributed to $\mu_{2}-\mathrm{Al}{ }_{v}-\mathrm{OH}$ groups on the (110) facet, vibrates at the same frequency. It is, therefore, impossible to judge from the IR spectra whether these $\mu_{2}-\mathrm{Al}_{\mathrm{V}}-\mathrm{OH}$ groups are also consumed by phosphate adsorption. However, the $\mu_{2}-\mathrm{Al}_{V}-\mathrm{OH}$ groups are linked to same surface $\mathrm{Al}$ sites as the $\mu_{1}-\mathrm{Al}_{\mathrm{V}}-\mathrm{OH}$ (110) groups, the difference being only the degree of hydration, leading either to two individual $\mathrm{OH}$ groups or one $\mathrm{OH}$ group bridging the two $\mathrm{Al}$ atoms ${ }^{14}$. One can, therefore, expect them to be affected by the phosphate adsorption in the same way.

Based on the existing literature ${ }^{1,31}$, we would have expected the most basic alumina surface site, $\mu_{1}-$ $\mathrm{Al}_{\mathrm{IV}}-\mathrm{OH}(110)^{14}$, vibrating at $3790 \mathrm{~cm}^{-1}$ to be very reactive towards phosphate species. However, Figure 1 show that the band at $3794 \mathrm{~cm}^{-1}$ is very weak on bare alumina and actually grows with increasing phosphate loading. This band at $3794 \mathrm{~cm}^{-1}$ formed upon phosphorous coverage also be explained by the presence of an $\mathrm{AlPO}_{4}$ phase. Indeed, $\mathrm{Peri}^{32}$ assigned a very intense band at $3800 \mathrm{~cm}^{-}$ ${ }^{1}$ to hydroxyl groups bonded to tetrahedral aluminum for an $\mathrm{AlPO}_{4}$ aerogel dried at $600^{\circ} \mathrm{C}$. At high $\mathrm{P}$ loadings, these $\mathrm{OH}$ groups could contribute to the $3794 \mathrm{~cm}^{-1}$ signal. At the highest phosphorus coverage of $4.5 \mathrm{at} / \mathrm{nm}^{2}$ all alumina $\mathrm{OH}$ groups were consumed and only the two bands typical of high surface area $\mathrm{AlPO}_{4}$, i.e. at 3794 and $3680 \mathrm{~cm}^{-1}$ were remaining.

The spectra are globally in agreement with the trends described by DeCanio et al. ${ }^{33}$ By plotting the area of the well-resolved bands of samples activated at $450^{\circ} \mathrm{C}$ versus the $\mathrm{P}$ coverage, the evolution of the different sites can be analysed in more detail (Figure 2). For example, the intensity of the band at $3730 \mathrm{~cm}^{-1}\left(\mu_{1}-\mathrm{Al} \mathrm{V}_{\mathrm{V}} \mathrm{OH}\right.$ on (110)) dropped significantly from 0 to $0.5 \mathrm{P} / \mathrm{nm}^{2}$, then stagnated; finally the band was progressively consumed. The band at $3770 \mathrm{~cm}^{-1}\left(\mu_{1}-\mathrm{Al}_{\mathrm{VI}}-\mathrm{OH}(100)\right)$ was partially consumed at low $\mathrm{P}$ loading and then followed the trend of the $3730 \mathrm{~cm}^{-1}$ band (although the corresponding $\mathrm{OH}$ groups are located on different facets). 


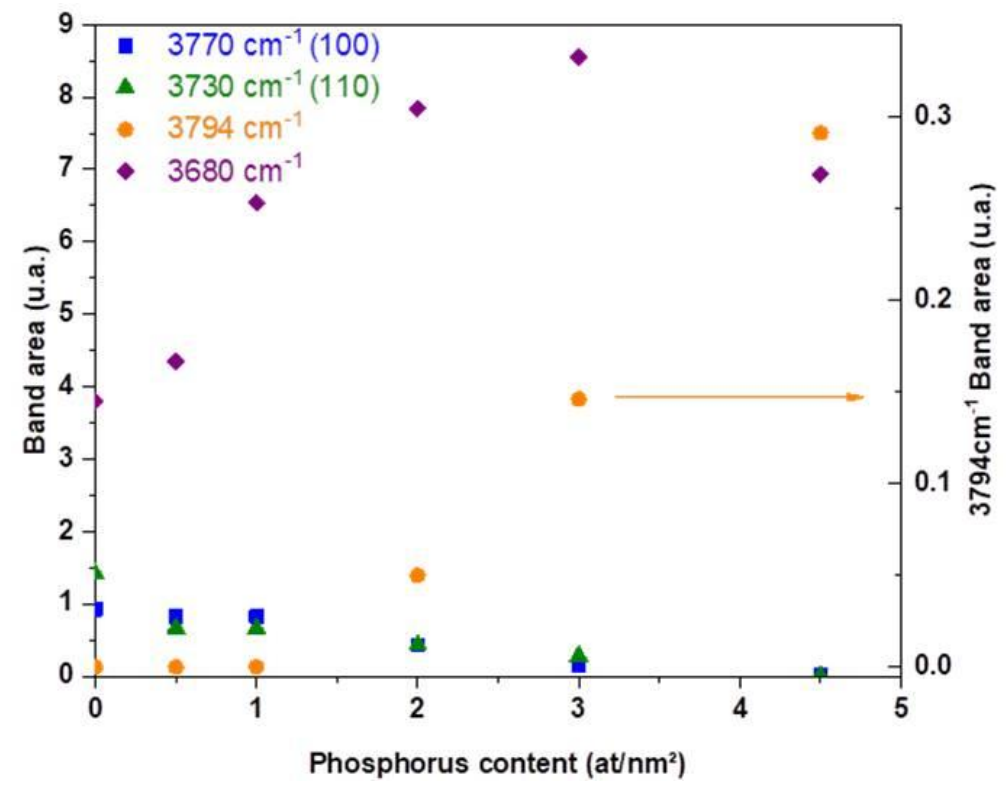

Figure 2 : Bands area evolution as a function of phosphorus coverage for the samples activated at $450^{\circ} \mathrm{C}$

The band at $3794 \mathrm{~cm}^{-1}$ rises in intensity above a phosphate loading of $1 \mathrm{at} / \mathrm{nm}^{2}$, suggesting that an $\mathrm{AlPO}_{4}$ might be formed above this phosphorus coverage. On the other hand, the $\mathrm{P}-\mathrm{OH}$ band at 3680 $\mathrm{cm}^{-1}$ increased in intensity as soon as phosphorus was deposited (the offset is due to the $\mathrm{Al}-\mathrm{OH}$ group at the same frequency) and even decreased at the highest phosphorus content (possibly due to condensation of phosphate groups).

van Eck et al. ${ }^{34}$, using ${ }^{27} \mathrm{Al}$ REDOR NMR, observed signals that mainly correspond to $\mathrm{AlPO}_{4}$ already at a loading corresponding to $1.7 \mathrm{at} / \mathrm{nm}^{2}$. Thus, it could be consistent with the presence of amorphous $\mathrm{AlPO}_{4}$ surface precipitate evocated for high phosphorus coverage in numerous previous studies ${ }^{1,35,36}$. However, the precise structure of the surface $\mathrm{AlPO}_{4}$ phase is hard to determine as this system has a tendency to form aluminum orthophosphates and does not crystallize easily ${ }^{37}$. We note that no $\mathrm{AlPO}_{4}$ phase was detectable in the XRD of our samples.

The use of transmission FTIR on dried samples is essential for obtaining insights in the surface sites involved in adsorption. Nevertheless, the pre-treatment applied before recording the spectrum allowing an easier interpretation of the data could slightly modify the surface and affect the surface hydroxyls and phosphate surface complexes speciation.

Consequently, in order to fully describe this hydrated state, phosphate adsorption process has been followed by in situ ATR-FTIR and by zetametry measurements for the rehydrated samples after drying stage.

\section{Characterization of the solid/liquid interface}

\section{ATR-FTIR}

ATR-FTIR characterization has been performed in order to compare the free dihydrogenophosphate ions in solution to the adsorbed and dried dihydrogenophosphate ions at the alumina surface (Erreur ! Source du renvoi introuvable.). 


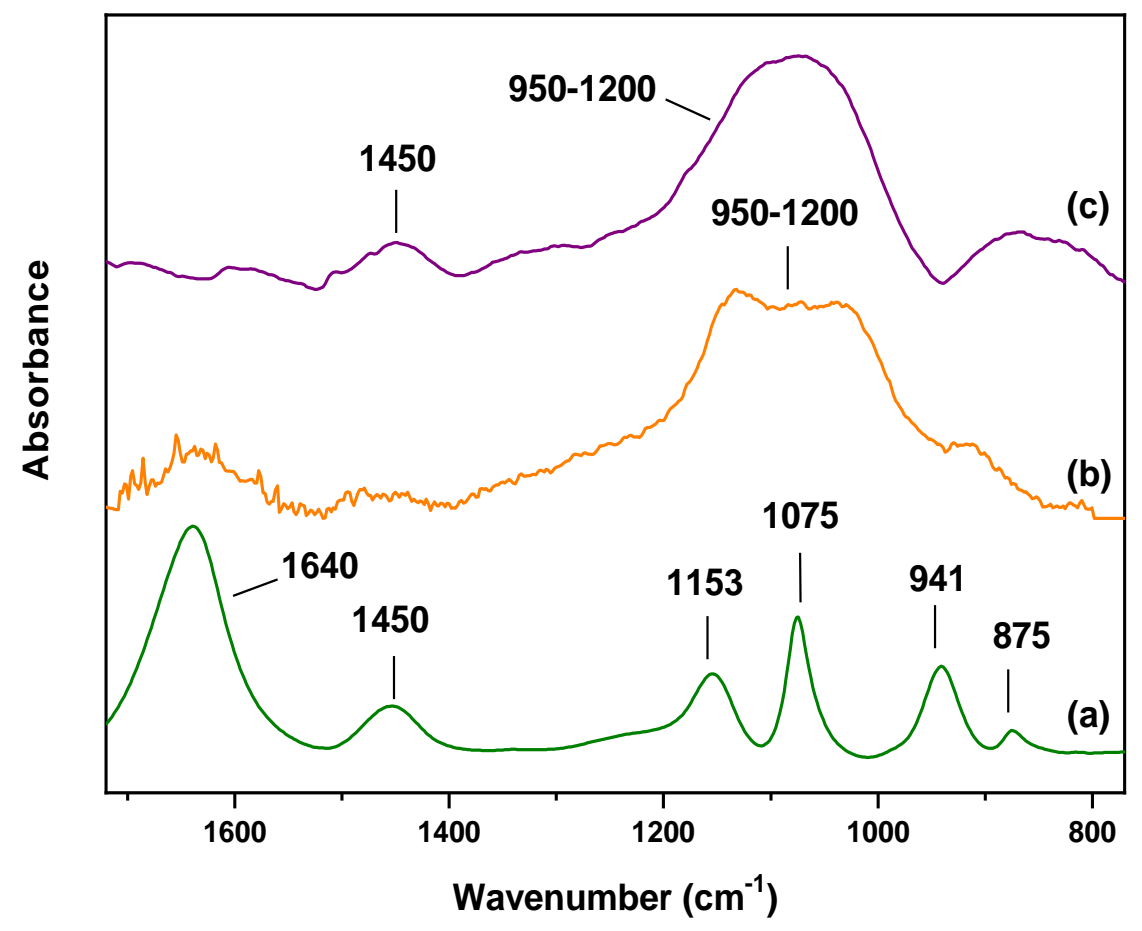

Figure 3 : ATR-IR spectra of (a) $\mathrm{NH}_{4} \mathrm{H}_{2} \mathrm{PO}_{4} \mathrm{O} .1 \mathrm{M}$, (b) in situ ATR infrared spectra of $\mathrm{H}_{2} \mathrm{PO}_{4}$ - at $10^{-3} \mathrm{M}$ in contact with $\mathrm{Y}^{-}$ $\mathrm{Al}_{2} \mathrm{O}_{3}$ at $\mathrm{pH} 4$, with coated $\mathrm{\gamma}-\mathrm{Al}_{2} \mathrm{O}_{3}$ crystal as background and (c) $\mathrm{H}_{2} \mathrm{PO}_{4}$ - adsorbed on $\mathrm{\gamma}-\mathrm{Al}_{2} \mathrm{O}_{3}$ at 1.8 at $/ \mathrm{nm}^{2}$ coverage and dried at $120^{\circ} \mathrm{C}$ for $6 \mathrm{~h}$ subtracted by $\mathrm{\gamma}-\mathrm{Al}_{2} \mathrm{O}_{3}$ spectra

The solution spectrum presents six well-defined bands in the region between $850 \mathrm{~cm}^{-1}$ and $1700 \mathrm{~cm}^{-}$ ${ }^{1}$. The two bands at $1450 \mathrm{~cm}^{-1}$ and $1640 \mathrm{~cm}^{-1}$ are not due to phosphate contribution and can be assigned to ammonium cation and $\mathrm{H}_{2} \mathrm{O}$ bending modes, respectively. The spectroscopic signal of the free dihydrogenophosphate is observed in the region $900-1200 \mathrm{~cm}^{-1}$, the doublet at 1153 and 1075 $\mathrm{cm}^{-1}$ is assigned to the asymmetric and symmetric vibration of the P-O bond, respectively, while the bands at 941 and $875 \mathrm{~cm}^{-1}$ correspond to the asymmetric and symmetric vibrations of the $\mathrm{P}-\mathrm{OH}$ bond $^{38}$. However, once adsorbed, the phosphate signal presents only one broad band covering the 950-1200 $\mathrm{cm}^{-1}$ region. The difference between the spectra suggests a strong interaction between the adsorbate and the support, which is in agreement with previous studies on aluminum (hydr)oxides ${ }^{10,8}$ and with the zetametry study performed in this work. This large band is observed both during the impregnation at the solid/solution interface (Erreur ! Source du renvoi introuvable.(b)) as well as after drying (Erreur ! Source du renvoi introuvable.(c)), thus indicating that solvent evaporation does not induce strong modifications on the adsorbed species. This information indicates the presence of a relatively stable complex already during the impregnation step, which can be related to a multidentate adsorption mode and/or a strong adsorption site. In the literature we find both examples, the presence of a direct bidentate complex at the interface before the solvent removal, observed by Lefèvre et $a l^{39}$ for the adsorption of uranyl on hematite, whereas Li et $a l^{12}$. found a change of the surface complex dentation mode from mono- to bidentate during the drying stage.

The change observed between the signal of the solution and the adsorbed phosphate is characteristic of a strong modification of the geometry of species by the formation of an innersphere complex through covalent bonding. This broad signal was found irrespective of the phosphorus content (Figure S2.A). It could be due to several contributions of phosphate compounds. 
Some authors have tried to decompose the signal observed after phosphate adsorption onto $\alpha-\mathrm{Al}_{2} \mathrm{O}_{3}$ and $\mathrm{\gamma}-\mathrm{Al}_{2} \mathrm{O}_{3}$. On $\mathrm{\gamma}-\mathrm{Al}_{2} \mathrm{O}_{3}$, Zheng et al. ${ }^{8}$ also observed a broad band between 950 and $1200 \mathrm{~cm}^{-1}$ due to phosphate adsorption at $\mathrm{pH} 4$ and monitored by in situ ATR-IR. By curve fitting, they found five subbands at 1126, 1080, 1017, 959 and $901 \mathrm{~cm}^{-1}$. They tentatively explained these bands by the simultaneous detection of inner and outer-sphere complexes and the presence of precipitated aluminum phosphate due to the $1080 \mathrm{~cm}^{-1}$ band associated to this phase. Their attribution is based on the comparison with the adsorption of phosphate onto iron (hydr)oxides. According to $\mathrm{DFT}^{40}$ and experimental studies ${ }^{17,41}$, they excluded the deprotonated bidentate binuclear (Erreur ! Source du renvoi introuvable.f) complex because of the presence of a band which could correspond to $P=O$. They concluded that the surface complex between phosphate and $\mathrm{\gamma}-\mathrm{Al}_{2} \mathrm{O}_{3}$ surface at low $\mathrm{pH}$ is either a monoprotonated bidentate binuclear complex (Erreur! Source du renvoi introuvable.g) or a deprotonated monodentate complex (Figure 4Erreur ! Source du renvoi introuvable.a). Nevertheless these assignments are not straightforward and they do not mention alumina surface sites involved during phosphate adsorption.

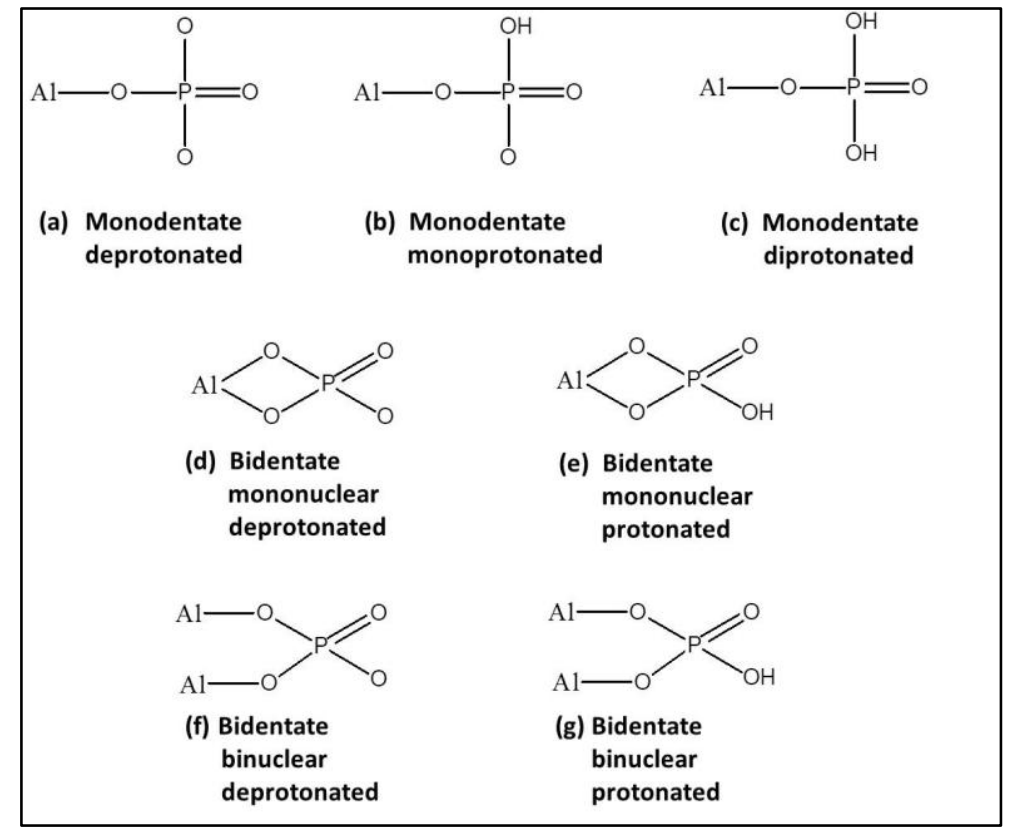

Figure 4 : Possible adsorption modes of monophosphate inner-sphere complexes at the $\mathrm{\gamma}-\mathrm{Al}_{2} \mathrm{O}_{3}$ surface (at low $\mathrm{P}$ coverage).

The second technique used to characterize the hydrated surface at a solid/liquid interface is the zetametry measurement to assess the surface charge modification induced by the adsorption of phosphate.

\section{Zetametry characterization}

The isoelectric point of a solid is characteristic of the oxide composition and structure, and is the result of the surface charge developed by the surface sites. The change in the density of surface hydroxyls by the specific adsorption of an ionic species along with the charge of the surface complex itself leads to a shift of the IEP. In Figure 5.A, the curves describing the evolution of the zeta potential as a function of $\mathrm{pH}$ for different phosphorus coverage are plotted. 

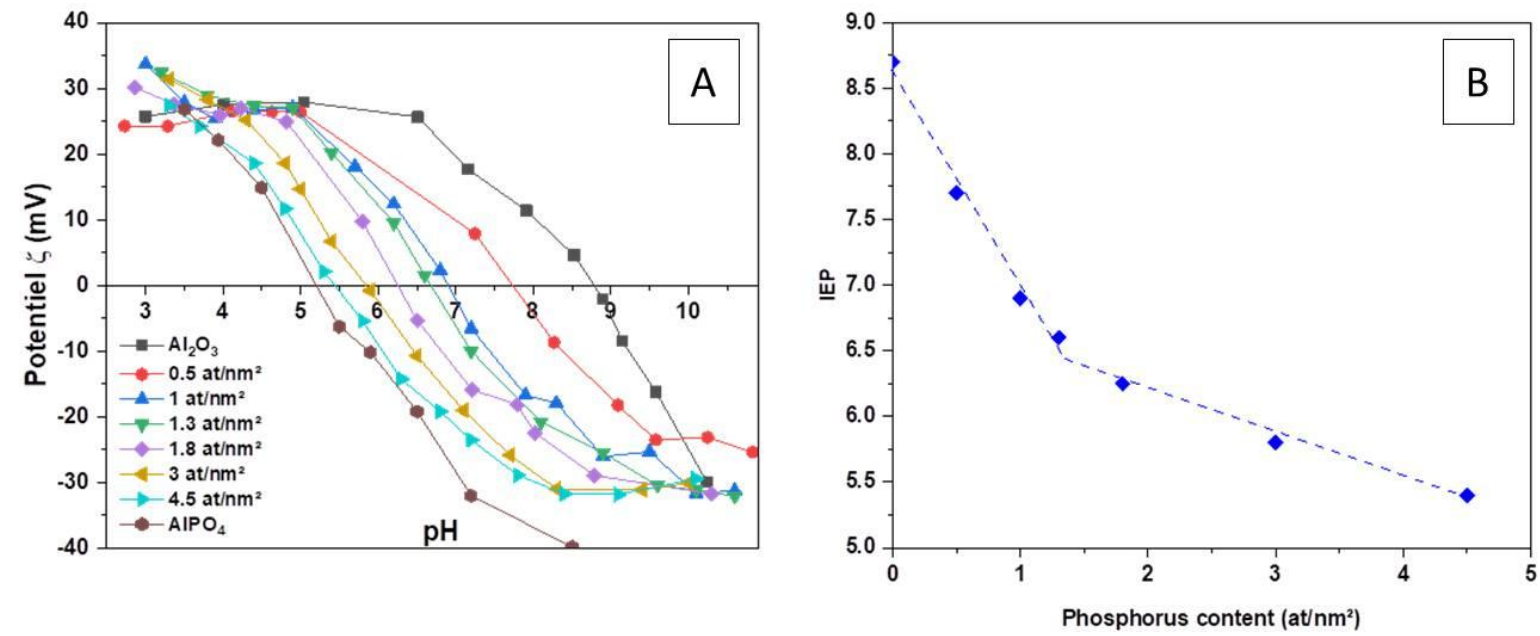

Figure 5 : (A) Zeta potential evolution as a function of $\mathrm{pH}$ for $\mathrm{Al}_{2} \mathrm{O}_{3}$, different phosphorus coverage on $\mathrm{Al}_{2} \mathrm{O}_{3}$ from 0 to 4.5 at $/ \mathrm{nm}^{2}$ and $\mathrm{AlPO}_{4}$ (lines are used as guidance for the reader) and (B) Evolution of the IEP as a function of phosphorus coverage $\left(\mathrm{at} / \mathrm{nm}^{2}\right.$ ) (lines are used as guidance for the reader).

Compared to $\gamma$-alumina, whose IEP is 8.8 , a shift towards lower values is observed with the increasing phosphorus coverage, converging towards the one of $\mathrm{AlPO}_{4}$ measured at 5.1. The shift indicates that the phosphate adsorption proceeds through the formation of an inner sphere complex at the alumina surface. A specific adsorption of anionic species leads to the compensation of positive charge and therefore to a decrease of the zeta potential, shifting the IEP to lower values. The impact of phosphorus coverage on the IEP value can be observed in Figure 5 : (A) Zeta potential evolution as a function of $\mathrm{pH}$ for $\mathrm{Al}_{2} \mathrm{O}_{3}$, different phosphorus coverage on $\mathrm{Al}_{2} \mathrm{O}_{3}$ from 0 to $4.5 \mathrm{at} / \mathrm{nm}^{2}$ and $\mathrm{AlPO}_{4}$ (lines are used as guidance for the reader) and (B) Evolution of the IEP as a function of phosphorus coverage $\left(\mathrm{at} / \mathrm{nm}^{2}\right.$ ) (lines are used as guidance for the reader)..B. where it can be seen that the latter becomes smaller with the increasing phosphorus surface concentration.

As already seen in the literature ${ }^{13}$, the IEP stabilization for very high phosphorus coverage (around $4.5 \mathrm{at} / \mathrm{nm}^{2}$ ) could be explained by the formation of an $\mathrm{AlPO}_{4}$ layer onto the surface as the IEP reaches the one of $\mathrm{AlPO}_{4}$ phase, 5.1 (between 4 and 5.6 in the litterature ${ }^{42}$ ). The latter observation is corroborated by the almost total disappearance of alumina $\mathrm{OH}$ signals in FTIR spectra at the highest phosphorus coverage.

Moreover, the slope of the curve IEP vs. P coverage changes at about $1.3 \mathrm{at} / \mathrm{nm}^{2}$, which suggests a change of the adsorption mechanism, i.e. of the surface speciation and/or of the adsorption sites involved. This change of slope is also found in the curves of zeta potential versus the phosphorus coverage at different $\mathrm{pH}$ (see Supporting Information, Figure S3). The surface modification above 1.3 at $/ \mathrm{nm}^{2}$ is tentatively attributed to the growth of the $\mathrm{AlPO}_{4}$ layer on the alumina surface. For identifying the processes at low coverage, a modelling approach is needed.

\section{PHREEQC modelling}

The information obtained by spectroscopy and zetametry, including knowledge from the existing literature, has been brought together in a surface complexation model using PHREEQC2 software. The modelling allows corroborating the interpretations of the results, as well as to obtain 
complementary information about the surface sites involved in the adsorption and on the geometry of the surface complex. Results from zetametry characterization indicate a two steps process with increasing sample P coverage: a first one leading to a sharp decrease of the IEP for low phosphorus coverage, a second one affecting the IEP to a lesser extent leading to its stabilization. The simulation of the evolution of IEP versus phosphate surface coverage of the Figure 5.B has been used to test the different possibilities for the surface speciation of hydrated samples.

The description of $\gamma$-alumina surface is based on the model built by Corral Valero et al. ${ }^{25}$ from the simulation of the acid-base titration curve of the surface. They used DFT information ${ }^{14,22}$ (density and charge of each site) combined to a MUSIC model ${ }^{43,44}$ in order to determine the pKa of each hydroxyl sites (Table S1 and S2 in the supporting information). They also used the two most developed faces on the alumina surface (100) and (110) in their respective proportion (20 and $80 \%$ respectively). These data implemented into PHREEQC software ${ }^{45}$ were associated with a basic Stern double layer model to described the solid/solution interface.

We have implemented this model with adsorbed phosphate species using four main hypotheses. First, the phosphate adsorption was considered as irreversible, i.e. it was not written as an equilibrium. The absence of desorption was experimentally observed: no phosphorus was released after 3 hours contact with an aqueous solution at $\mathrm{pH}$ between 4 and 9 or with a solution at high ionic strength I=0.5 M (data not shown here). The second hypothesis concerns the denticity of the inner sphere complex: only bidentate binuclear and monodentate species are considered. Indeed, in a recent solid-state NMR study ${ }^{12}$ of phosphate adsorption on aluminum (hydr)oxides was found to be monodentate $(<3 \%)$ or bidentate $(>97 \%)$ in a wet environment. For dried samples, the bidentate adsorption mode was the only one detected. The third hypothesis concerns the possible formation of an amorphous $\mathrm{AlPO}_{4}$ phase, as evocated in numerous studies ${ }^{1,35,36}$. AlPO $\mathrm{Is}_{4}$ taken into account only for second part of the IEP curve (P coverage $>1.3 \mathrm{at} / \mathrm{nm}^{2}$ ) when all the surface sites explaining the first part of the curve are totally consumed. The last hypothesis is about the possible protonation of surface complexes. For the complex used in the model, only one acidity constant is used to describe its protonation. The pKa selected corresponds to the second pKa of phosphoric acid, i.e. 7.20. Indeed, the other two pKa (2.15 and 12.32) are too far from the $\mathrm{pH}$ range used during the zetametry study (3.5-11).

The simulations performed using this model do not imply any fitting procedure. The main objective is to compare our data to different scenarios, involving different adsorption sites and processes (complex formation and precipitation), in order to simulate the experimental IEP shift observed in Figure 5.B.

In the first scenario, a monodentate adsorption was considered to describe the first part of the curve. Several sites have been tested in order to retrieve the sharp decrease observed experimentally (Figure 6). 


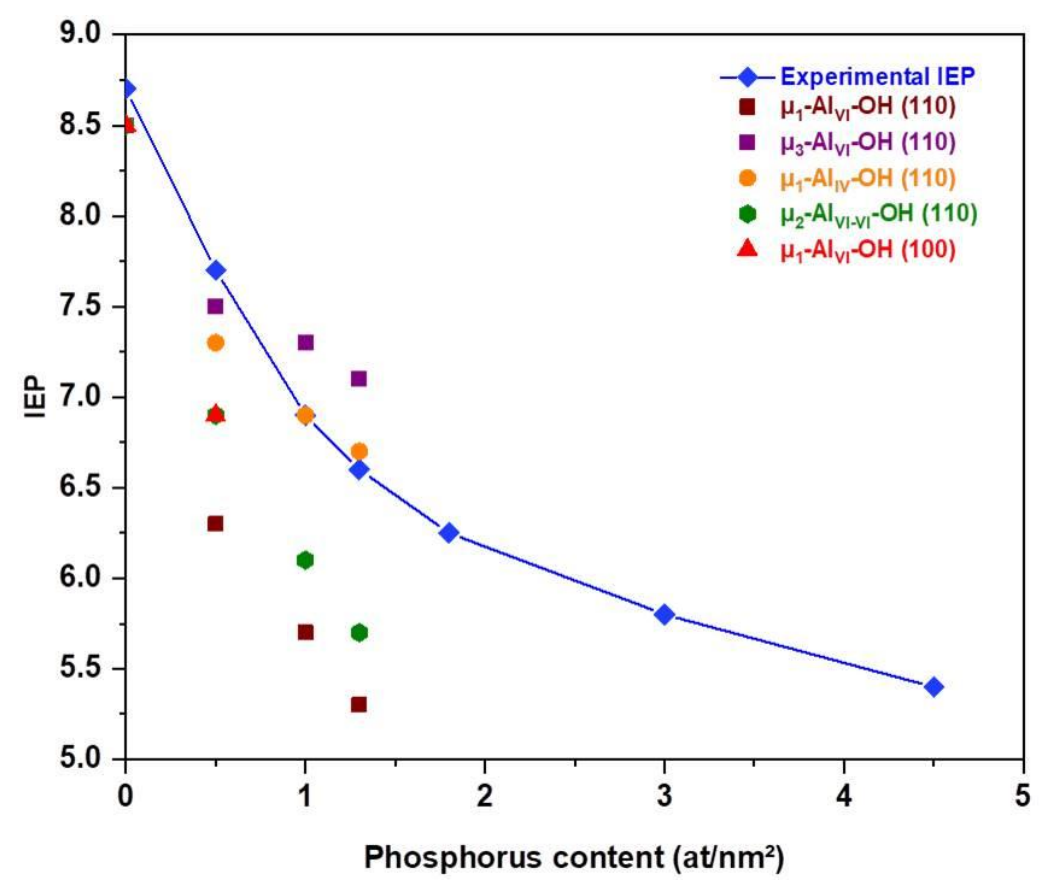

Figure 6 : Calculated IEP as a function of $\mathrm{P}$ coverage $\left(\mathrm{at} / \mathrm{nm}^{2}\right)$ for a monodentate surface complex on different alumina surface sites (line is used as guidance for the reader).

The presence of $\mu_{1}-\mathrm{Al} \mathrm{VI}^{-} \mathrm{OH}(110)$, which does not appear in the IR band assignment of Table 2, is due at the solid/liquid interface to the dissociative adsorption of water on $\mathrm{Al}_{\mathrm{V}}$ during the hydration of alumina. The too sharp decrease observed for a phosphate adsorption on $\mu_{1}-\mathrm{Al} \mathrm{Vl}_{1} \mathrm{OH}$ (110) and the $\mu_{2}-\mathrm{Al}_{\mathrm{VI}-\mathrm{V}}-\mathrm{OH}(110)$ is explained by the change of the surface charge during the adsorption. According to their protonation constant, these sites are mainly positively charged ( +0.5 and +0.25 , respectively). Thus the adsorption of an anionic species leads to the replacement of positive charge by negative surface complex involving a strong decrease of the IEP due to an increase in the number of protons needed to compensate the more negative surface charge.

Experimentally, a small consumption of $\mu_{1}-\mathrm{Al}_{\mathrm{vl}}-\mathrm{OH}(100)$ is observed as the $3770 \mathrm{~cm}^{-1}$ band area weakly decreases (Figure 2) for the lowest phosphorus content which indicates that only a small fraction of this sites are consumed. Moreover, these sites are located on the (100) face which represents only $20 \%$ of the whole surface, their consumption would have a very minor impact on the IEP. Consequently, phosphate adsorption on these sites could be consider as negligible.

To describe the first part of the curve, a monodentate adsorption onto the alumina surface site $\mu_{1^{-}}$ $\mathrm{Al}_{\mathrm{IV}}-\mathrm{OH}(110)$ is the best scenario to retrieve the experimental trend. The $\mu_{1}-\mathrm{Al} \mathrm{I}_{\mathrm{VV}}-\mathrm{OH}(110)$ is mainly negatively charged -0.25 and compensated by positive surface sites on the bare surface. Their consumption to form a negative surface complex (equation 1 ) is then compensated by the positively charged surface sites and the addition of a proton. As a part is already compensated by the positive surface sites, a smaller quantity of protons is needed which explains the smaller decrease of the IEP.

The same behaviour is observed for the $\mu_{3}-\mathrm{Al} \mathrm{V}_{\mathrm{VI}} \mathrm{OH}(110)$ as they are both -0.5 and +0.5 charged on the $\mathrm{pH}$ range studied and would need an even lower number of protons to compensate a negative surface complex, expressed by a smaller decrease of the IEP. The $\mu_{3}-\mathrm{Al}_{\mathrm{VI}}-\mathrm{OH}$ (110) can, thus, not explain behaviour at higher phosphorus coverage. 
This $\mu_{1}-\mathrm{Al}_{\mathrm{IV}}-\mathrm{OH}(110)$ which is known to be the most basic and reactive site on alumina ${ }^{46-48}$, adsorption on this site models best the zetametry data. Thus, it could be considered as the first reaction site for the phosphate adsorption according to equation 1.

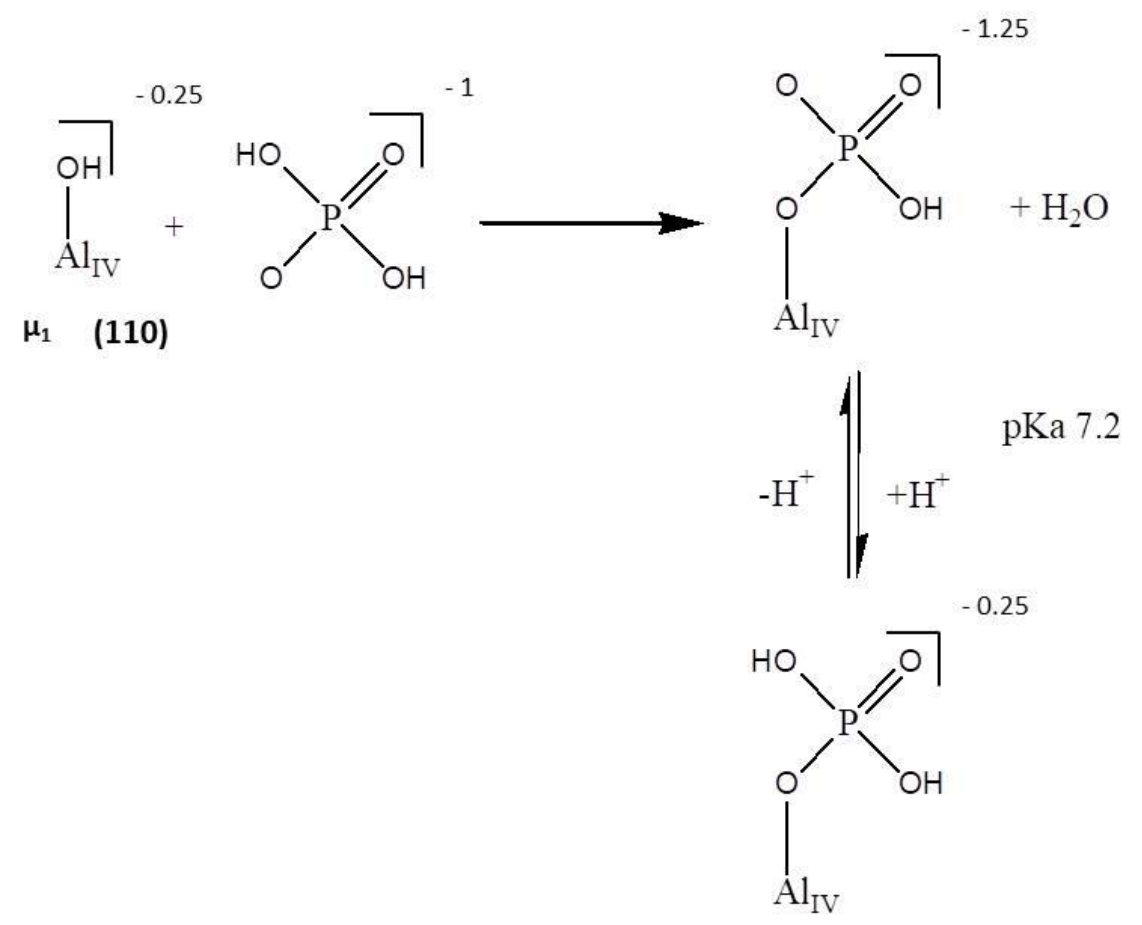

Eq.1

Experimentally, a strong decrease of the band at $3730 \mathrm{~cm}^{-1}$ is observed for the lowest phosphorus content (Figure 2) for the activated sample. This band corresponds to $\mu_{1}-\mathrm{Al}_{\mathrm{v}}-\mathrm{OH}$ on the (110) facet and can be seen at the solid/liquid interface as an aluminum atom coordinated to a non-dissociated water molecule, thus having no charge (first line on Table S1). Our surface complexation model based on the IEP shift cannot integrate this surface site as its consumption would not impact the surface charge, the zeta potential and consequently the IEP shift. However, its participation could be explained by the formation of a bidentate complex using both $\mu_{1}-\mathrm{Al}_{\mathrm{IV}}-\mathrm{OH}$ and $\mu_{1}-\mathrm{Al}_{\mathrm{V}}-\mathrm{OH}$. The bidentate could be directly formed at the interface, or a during the drying process starting from the monodentate form as illustrated by the equation 2 . This hypothesis is strengthened by the proximity of these two sites on the same alumina facet $(110)^{14}$. In support of that hypothesis, we also note that Li et $a .^{12}$ observed the presence of bidentate binuclear complex after air-drying of samples and a monodentate at wet conditions.<smiles>O=P(O)(O)O[Al]</smiles><smiles>O=C(O)CO</smiles><smiles>O=P(O)(O[AlH2])O[AlH2]</smiles> 
The scenario described above represents very well representative of the sharp decrease of the IEP value at low phosphorus coverage. However, the maximum quantity of $\mu_{1}-\mathrm{Al}_{\mathrm{IV}}-\mathrm{OH}$ sites corresponds to $1.2 \mathrm{P} / \mathrm{nm}^{2}$, i.e. the reaction with this specific site cannot explain what happens at higher phosphorus loadings. Moreover, the formation of this complex does not explain the concomitant decrease of the $3770 \mathrm{~cm}^{-1}$ and $3730 \mathrm{~cm}^{-1}$ bands corresponding to $\mu_{1}-\mathrm{Al}_{\mathrm{V} 1}-\mathrm{OH}$ (100) and $\mu_{1}-\mathrm{Al}_{\mathrm{v}}-\mathrm{OH}$ (110) at higher phosphate loadings. Consequently, a second scenario is added to retrieve the whole experimental trend.

The second scenario (Figure 7) differs from the first one by the fact that no complex is added to the model but a precipitation process is implemented. The precipitation of an $\mathrm{AlPO}_{4}$ phase relies on the observation of DeCanio et al. ${ }^{33}$ of a crystalline phase of $\mathrm{AlPO}_{4}$ after calcination on a surface containing more than $7.9 \mathrm{at} / \mathrm{nm}^{2}$ but also of amorphous $\mathrm{AlPO}_{4}$ at phosphorus loadings superior to 3.5 $\mathrm{at} / \mathrm{nm}^{2}$ using ${ }^{31} \mathrm{P}$ NMR. This phase is evocated at even lower surface coverage $\left(1.7 \mathrm{at} / \mathrm{nm}^{2}\right)$ by Van Eck et al. ${ }^{34}$ using ${ }^{27} \mathrm{Al} \mathrm{NMR}$. The scenario is also supported by the evolution trend of the IEP reaching a value around the one of $\mathrm{AlPO}_{4}$ for the highest phosphorus coverage. Moreover, a strong indicator is the decrease of all infrared bands signals without distinction of $\mathrm{y}-\mathrm{Al}_{2} \mathrm{O}_{3}$ facets (Figures 1 and 2). Thus, it is thought that the $\mathrm{AlPO}_{4}$ could progressively cover the entire surface from a threshold value, as soon as all the $\mu_{1}-\mathrm{Al}_{\mathrm{IV}}-\mathrm{OH}$ are consumed. It has been calculated that to retrieve the IEP value at 1.8 at $/ \mathrm{nm}^{2}$ the coverage of $\mathrm{AlPO}_{4}$ should be around $15 \%, 35 \%$ at $3 \mathrm{at} / \mathrm{nm}^{2}$ coverage, while for the highest value at $4.5 \mathrm{at} / \mathrm{nm}^{2}$ it should be around $75 \%$. After implementing a phase with an IEP of 5.1 at these different percentages, the model is able to reproduce the entire curve of the experimental data (Figure 7). The simulation shows that a threshold at $1.3 \mathrm{P} / \mathrm{nm}^{2}$ would correspond to the beginning of the precipitation, and the ATR infrared spectra in these two domains have been compared (Figure S2). They follow two trends: up to $1.3 \mathrm{P} / \mathrm{nm}^{2}$, the intensity increase without evolution of the shape, while above this threshold, a shift appears in the total signal, what is consistent with a mixture of two components. Unfortunately, this evolution is not pronounced enough to yield satisfactory results in a decomposition approach.

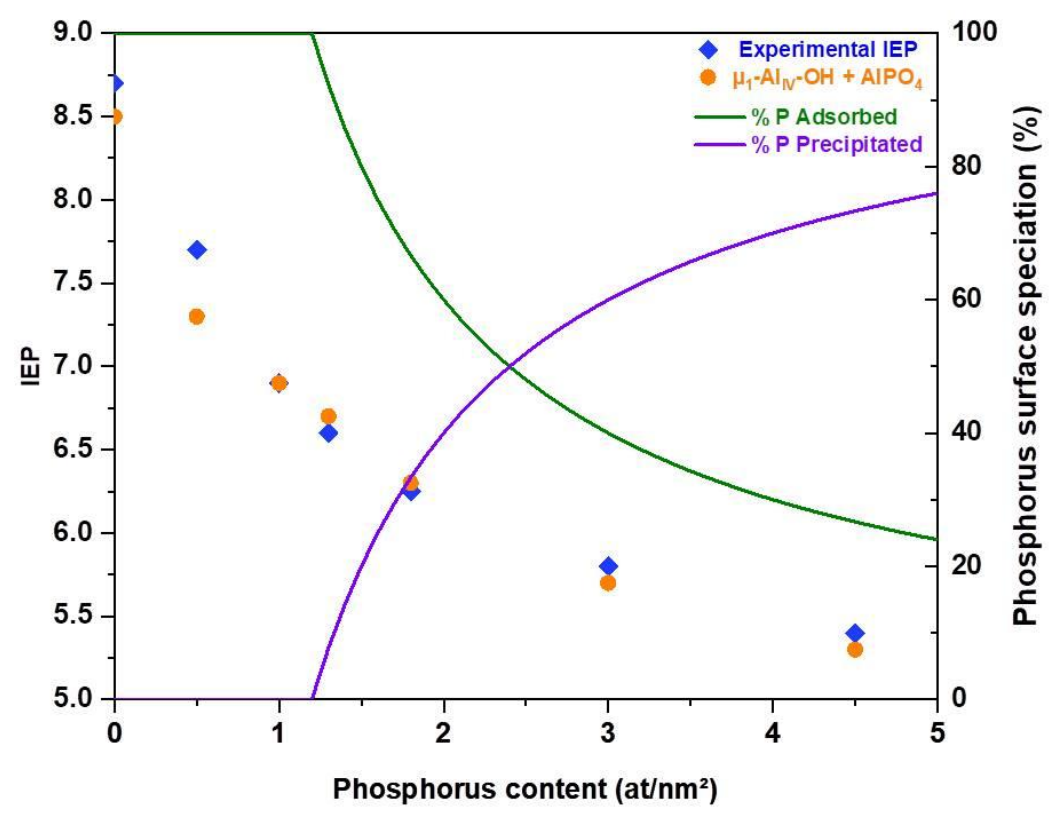

Figure 7 : Calculated IEP as a function of $\mathrm{P}$ coverage $\left(\mathrm{at} / \mathrm{nm}^{2}\right)$ for a monodentate on $\mu_{1}-\mathrm{Al}_{\mathrm{IV}}-\mathrm{OH}$ followed by an $\mathrm{AlPO}_{4}$ precipitation. 
The model developed here highlights a two-step process in the adsorption involving one surface complex on a single adsorption site and one precipitation process. The FTIR shows a strong participation of all surface hydroxyls from a threshold value and suggests the formation of an $\mathrm{AlPO}_{4}$ phase, supported by zetametry measurements. The model goes further in the description by pointing out the role of $\mu_{1}-\mathrm{Al}_{\mathrm{IV}}-\mathrm{OH}$ in the first complex adsorption, which was not obvious on FTIR spectra and supports the precipitation process. This complex explains the first part of the curve and is formed until the total $\mu_{1}-\mathrm{Al}_{\mathrm{IV}}-\mathrm{OH}$ density is consumed, explaining the presence of a threshold value. Beyond this coverage, a precipitation process is implemented which explain both the stabilization of the IEP around the one of pure $\mathrm{AlPO}_{4}$ as well as the formation of a band at $3794 \mathrm{~cm}^{-1}$ on infrared characterization.

\section{Conclusions}

The complementarity between characterization of solid/liquid interface and a model approach has proven to be useful in order to understand which complex and $\mathrm{y}-\mathrm{Al}_{2} \mathrm{O}_{3}$ surface sites are involved in the phosphate adsorption process. According to our characterization data and PHREEQC modelling, phosphate ions first react with $\mu_{1}-\mathrm{Al}_{\mathbb{V}}-\mathrm{OH}$ forming a monodentate complex and/or a bidentate by involving neighbouring $\mu_{1}-\mathrm{Al}_{\mathrm{V}}-\mathrm{OH}$ on the (110) surface. All these reactive sites are consumed, forming a maximum coverage of the surface complex of 1.2 at $\mathrm{P} / \mathrm{nm}^{2}$, and explaining at the same time the change of the slope observed experimentally by zetametry measurements. For phosphate loadings higher than this value, the formation of $\mathrm{AIPO}_{4}$ is invoked to explain both the stabilization of the IEP and the presence of a growing band at $3794 \mathrm{~cm}^{-1}$ on the FTIR spectra.

To our knowledge, this is the first time a two-step mechanism highlighting a threshold value and describing the alumina surface hydroxyls and surface complex involved is proposed. The determination of the mechanism of adsorption and the complex formed by PHREEQC modelling of zetametry measurement presented here represents a novel and original approach from the ones evocated in the literature. This model includes parameters related to the surface groups as well as the surface complex. The charge of the surface groups, the one of the complex, its possible protonation and its density are the key parameters to model the zetametry results and complete the experimental data. Next steps will include the refinement of the PHREEQC model by theoretical verification of the adsorption mode proposed by DFT calculations at wet conditions as well as dry one. This ongoing work is necessary to precise the adsorption mode on a dried surface as the removal of water may result in a change of the dentation mode.

\section{Acknowledgments}

This work is part of the "RatiOnAl Design for CATalysis" (ROAD4CAT) industrial chair, project IDEXLYON funded by the French National Research Agency (ANR-16-IDEX-0005) and the Commissariat-General for Investment (CGI) within the framework of Investissements d'Avenir program ("Investment for the future"). 



\section{References}

1. Iwamoto R, Grimblot J. Influence of Phosphorus on the Properties of Alumina-Based Hydrotreating Catalysts. Adv Catal. 1999 ; 44(C) : 417-503.

2. Sio F, Wang S, Xu D, Zhao J, Zheng W, Hu C. Catalysis Science \& Technology Investigation of the effects of phosphorus on the selective hydrodeoxygenation of anisole over an $\mathrm{Fe} / \mathrm{SiO}_{2}$ catalyst. Catal Sci Technol. 2019 : 5712-5724.

3. Li W, Li Y, Fu H, Yang G, Zhang Q, Chen S. Phosphorus doped $\mathrm{Co}_{9} \mathrm{~S}_{8} @ \mathrm{CS}$ as an excellent airelectrode catalyst for zinc- air batteries. Chem Eng J. 2020 ; 381 : 122683.

4. Atanasova P, Halachev T, Uchytil J, Kraus M. Effect of phosphorus on the surface concentration of molybdenum and nickel in the oxide form of nickel-molybdenum/alumina catalysts and on their hydrodesulphurization activity. Appl Catal. 1988 ; 38(2) : 235-240.

5. Fltz CW, Rase HF. Effects of Phosphorus on Nickel-Molybdenum Hydrodesulfurization/Hydrodenitrogenation Catalysts of Varying Metals Content. Ind Eng Chem Prod Res Dev. 1983; 22 (1) : 40-44.

6. Morales A, Ramirez de Agudelo MM, Hernandez F. Adsorption Mechanism of Phosphorus on Alumina. Appl Catal. 1988 ; (41) : 261-271.

7. Atanasova $\mathrm{P}$, López Cordero R, Mintchev L, Halachev $\mathrm{T}$, López Agudo A. Temperature programmed reduction of the oxide form of $\mathrm{PNiMo} / \mathrm{Al}_{2} \mathrm{O}_{3}$ catalysts before and after water extraction. Appl Catal A Gen. 1997 ; 159(1-2) : 269-289.

8. Zheng TT, Sun ZX, Yang XF, Holmgren A. Sorption of phosphate onto mesoporous $Y$-alumina studied with in-situ ATR-FTIR spectroscopy. Chem Cent J. 2012;6(1):1-11.

9. Arai Y, Sparks DL. ATR-FTIR spectroscopic investigation on phosphate adsorption mechanisms at the ferrihydrite-water interface. J Colloid Interface Sci. 2001 ;241 (2) :317-326.

10. Del Nero $M$, Galindo C, Barillon R, Halter E, Madé B. Surface reactivity of $\alpha-\mathrm{Al}_{2} \mathrm{O}_{3}$ and mechanisms of phosphate sorption: In situ ATR-FTIR spectroscopy and $\zeta$ potential studies. $J$ Colloid Interface Sci. $2010 ; 342$ (2) : 437-444.

11. Hesterberg D, Beauchemin S. Changes in Phosphate Bonding as Affected by Level of Adsorption on Oxide Minerals.; 2000.

12. Li W, Feng X, Yan Y, Sparks DL, Phillips BL. Solid-State NMR Spectroscopic Study of Phosphate Sorption Mechanisms on Aluminum (Hydr)oxides. Environ Sci Technol. 2013 ; 47 : 8308-8315.

13. Cordero RL, Gil Llambías FJ, Palacios JM, Fierro JLG, Agudo AL. Surface changes of alumina induced by phosphoric acid impregnation. Appl Catal. $1989 ; 56$ (1) : 197-206.

14. Digne $M$, Sautet $P$, Raybaud $P$, Euzen $P$, Toulhoat $H$. Hydroxyl Groups on $\gamma$-Alumina Surfaces : A DFT Study. J Catal. $2002 ; 211$ : 1-5.

15. Kubicki JD, Paul KW, Kabalan L, et al. ATR-FTIR and Density Functional Theory Study of the Structures, Energetics, and Vibrational Spectra of Phosphate Adsorbed onto Goethite. Langmuir. $2012 ;(28)$ : 14573-14587.

16. Parfitt RL. Phosphate reactions with natural allophane, ferrihydrite and goethite. I soil Sci. $1989 ;(40): 359-369$. 
17. Tejedor-tejedor MI, Anderson MA. Protonation of Phosphate on the Surface of Goethite As Studied by CIR-FTIR and Electrophoretic Mobility. Langmuir. 1990 ;6 (3) : 602-611.

18. Persson $\mathrm{P}$, Nilsson N, Sjöberg S. Structure and Bonding of Orthophosphate lons at the Iron Oxide-Aqueous Interface. J Colloid Interface Sci. 1996 ; (177) : 263-275.

19. Rahnemaie R, Hiemstra T, van Riemsdijk WH. Geometry, Charge Distribution, and Surface Speciation of Phosphate on Goethite. Langmuir. 2007 ; (23) : 3680-3689.

20. Morales A, Ramirez De Agudelo M, Hernandez F. Adsorption mechanism of phosphorus on alumina. Appl Catal. $198841: 261-271$.

21. Mikaml N, Sasakl M, Kazuakl Hachlya, R. D. Astumlan, Tetsuya I, Yasunaga T. Kinetics of the Adsorption-Desorption of Phosphate on the $y-\mathrm{Al}_{2} \mathrm{O}_{3}$ Surface Using the Pressure-Jump Technique. J Phys Chem. 1983; 87: 1454-1458.

22. Digne $M$, Sautet $P$, Raybaud $P$, Euzen $P$, Toulhoat $H$. Use of DFT to achieve a rational understanding of acid - basic properties of $p$-alumina surfaces. J Catal. $2004 ; 226$ : 54-68.

23. Réocreux R, Jiang $T$, lannuzzi M, Michel $C$, Sautet P. Structuration and Dynamics of Interfacial Liquid Water at Hydrated -Alumina Determined by ab Initio Molecular Simulations: Implications for Nanoparticle Stability. ACS Appl Nano Mater. 2018 ;1 (1) : 191-199.

24. Ngouana-Wakou BF, Cornette P, Corral Valero M, Costa D, Raybaud P. An Atomistic Description of the $\gamma$-Alumina/Water Interface Revealed by Ab Initio Molecular Dynamics. $J$ Phys Chem C. 2017 ; 121(19) : 10351-10363.

25. Corral Valero M, Prelot B, Lefèvre G. MUSIC Speciation of $\mathrm{y}-\mathrm{Al}_{2} \mathrm{O}_{3}$ at the Solid Liquid Interface: How DFT Calculations Can Help with Amorphous and Poorly Crystalline Materials. Langmuir. $2019 ; 35$ (40) : 12986-12992.

26. Park J, Regalbuto JR. A Simple, Accurate Dtermination of Oxide PZC and the Strong Buffering Effect of Oxide Surfaces at Incipient Wetness. J Colloid Interface Sci. 1995 ; 175 : 239-252.

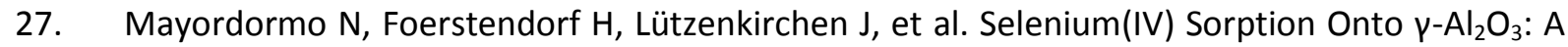
Consistent Description of the Surface Speciation by Spectroscopy and Thermodynamic Modeling. Environ Sci Technol. 2018;52(2):581-588.

28. Hiemstra T, Yong H, Riemsdijk WH Van. Interfacial Charging Phenomena of Aluminum (Hydr) oxides. Langmuir. $1999 ; 15:$ 5942-5955.

29. Lützenkirchen J. Comparison of 1-pK and 2-pK versions of surface complexation theory by the goodness of fit in describing surface charge data of (hydr)oxides. Environ Sci Technol. 1998; 32 (20) : 3149-3154.

30. Beaufils J, Laue-langevin I. Détermination, par diffraction differentielle de neutrons, des faces cristallines exposées par des supports de catalyseurs en poudre. J Chim Phys. 1981 ; 78 (4) : 347-352.

31. Chakrabarti A, Wachs IE. Molecular Structure - Reactivity Relationships for Olefin Metathesis by $\mathrm{Al}_{2} \mathrm{O}_{3}$ Supported Surface $\mathrm{MoO}_{x}$ Sites. ACS Catal. 2018 ; (8) : 949-959.

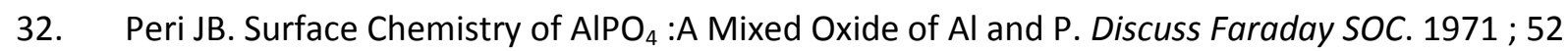
: 56-65.

33. Decanio EC, Edwards JC, Scalzo TR, Storm DA, Bruno JW. FT-IR and solid-state NMR 
investigation of phosphorus promoted hydrotreating catalyst precursors. J Catal. $1991 ; 132$ (2) : 498-511.

34. van Eck ERH, Kentgens APM, Kraus $H$, Prins R. A Solid State Double Resonance NMR

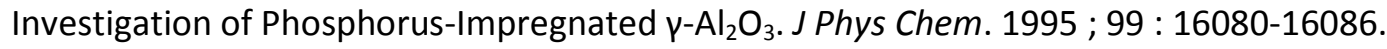

35. van Veen J a. R, Hendriks P a. JM, Romers EJGM, Andrea RR. Chemlstry of Phosphomolybdate Adsorption on Alumina Surfaces. 1. The Molybdate/Alumlna System. J Phys Chem. 1990 ; 94 (17) : 5275-5282.

36. Mangnus PJ, Van Veen JAR, Eijsbouts S, De Beer VHJ, Moulijn JA. Structure of phosphorus containing $\mathrm{CoOMoO}_{3} / \mathrm{Al}_{2} \mathrm{O}_{3}$ catalysts. Appl Catal. 1990 ; 61 (1) : 99-122.

37. Kniep R. Orthophosphates in the Ternary System $\mathrm{Al}_{2} \mathrm{O}_{3}-\mathrm{P}_{2} \mathrm{O}_{5}-\mathrm{H}_{2} \mathrm{O}$. Angew Chemie. $1986 ; 25$ : 525-534.

38. Klähn $M$, Mathias $G$, Kötting $C$, et al. IR spectra of phosphate ions in aqueous solution: Predictions of a DFT/MM approach compared with observations. J Phys Chem A. $2004 ; 108$ (29) : 6186-6194.

39. Lefèvre $G$, Noinville $S$, Fédoroff $M$. Study of uranyl sorption onto hematite by in situ attenuated total reflection - infrared spectroscopy. J Colloid Interface Sci. $2006 ; 296$ : 608613.

40. Kwon KD, Kubicki JD. Molecular orbital theory study on surface complex structures of phosphates to iron hydroxides: Calculation of vibrational frequencies and adsorption energies. Langmuir. $2004 ; 20$ (21) : 9249-9254.

41. Elzinga EJ, Sparks DL. Phosphate adsorption onto hematite: An in situ ATR-FTIR investigation of the effects of $\mathrm{pH}$ and loading level on the mode of phosphate surface complexation. $J$ Colloid Interface Sci. 2007 ; 308 (1) : 53-70.

42. Marek Kosmulski. Surface Charging and Points of Zero Charge (Surfactant Science). CRC Press; 2009.

43. Hiemstra $T$, Venema $P$, Van Riemsdijk $W H$. Intrinsic proton affinity of reactive surface groups of metal (hydr)oxides: The Bond valence principle. J Colloid Interface Sci. $1996 ; 184$ : 680-692.

44. Hiemstra T, Wolthers M. A Surface StructuralAapproach to Ion Adsorption: The Charge Distribution (CD) Model. J Colloid Interface Sci. 1996 ; 179 (179) : 488-508.

45. Parkhurst DL, Appelo CAJ. User's guide to PHREEQC (version 2) - A computer program for speciation, batch reaction, one-dimensional transport, and inverse geochemical calculations. Water Resour Investig. 1999;(USGS).

46. Lewis JM, Kydd RA. Adsorption mechanism of phosphoric acid on $\mathrm{\gamma}$-alumina. J Catal. 1991 ; $132(2)$ : 465-471.

47. Veen RJA van, Jonkers G, Hesselink WH. Interaction of Transition-metal Acetylacetonates with y-Al ${ }_{2} \mathrm{O}_{3}$, Surfaces. J Chem SOC, Faraday Trans I. $1989 ; 85$ (2 ): 389-413.

48. Nicosia $\mathrm{D}$, Prins R. The effect of glycol on phosphate-doped $\mathrm{CoMo} / \mathrm{Al}_{2} \mathrm{O}_{3}$ hydrotreating catalysts. J Catal. $2005 ; 229$ (2) : 424-438. 


\section{Phosphate adsorption on $\gamma$-alumina: a surface complex model based}

\section{on surface characterization and zeta potential measurements}

Teddy Roy, Dorothea Wisser, Mickaël Rivallan, Manuel Corral Valero, Thibaut Corre, Olivier Delpoux, Gerhard D. Pirngruber, Grégory Lefèvre

\section{SUPPORTING INFORMATION}
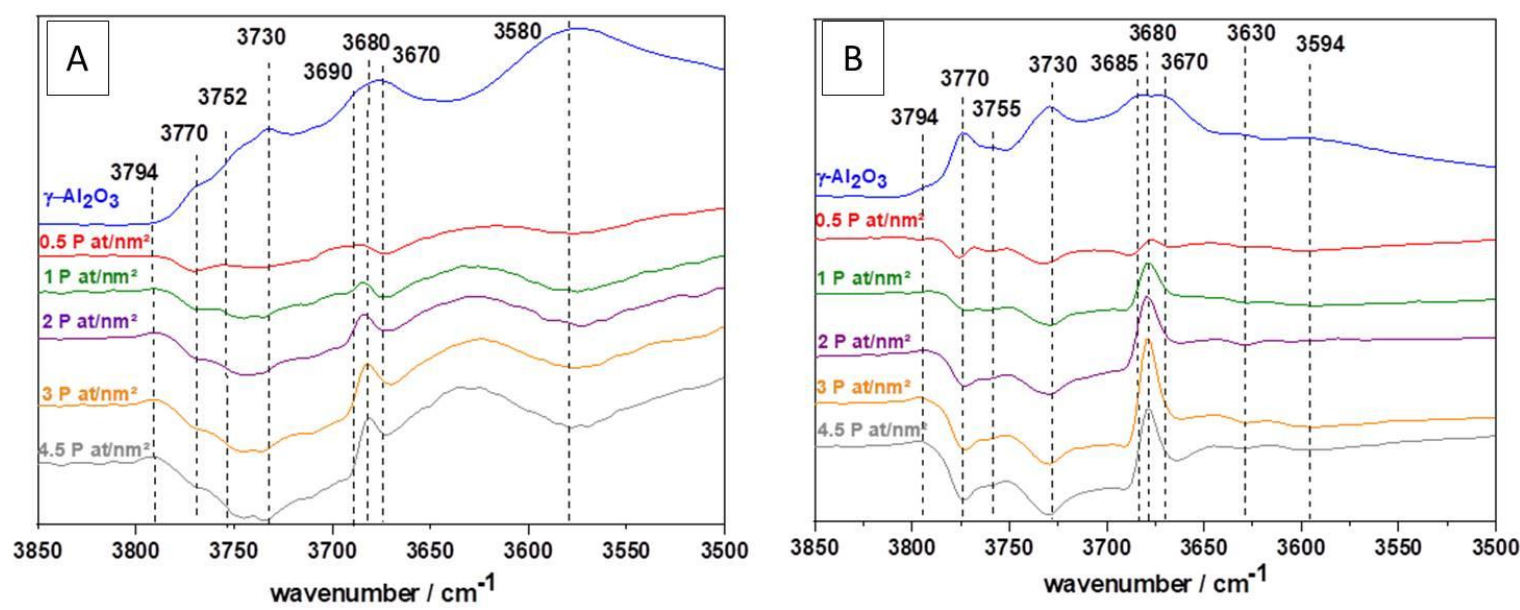

Figure $\mathrm{S} 1$ : Transmission FT-IR difference spectra between $\mathrm{y}-\mathrm{Al}_{2} \mathrm{O}_{3}$ and phosphated alumina at different phosphorus content (from 0.5 to 4.5 at $/ \mathrm{nm}^{2}$ ) after activation (A) at room temperature or (B) $450^{\circ} \mathrm{C}$ under vacuum $\left(10^{-5} \mathrm{mbar}\right), \mathrm{OH}$ stretching region.
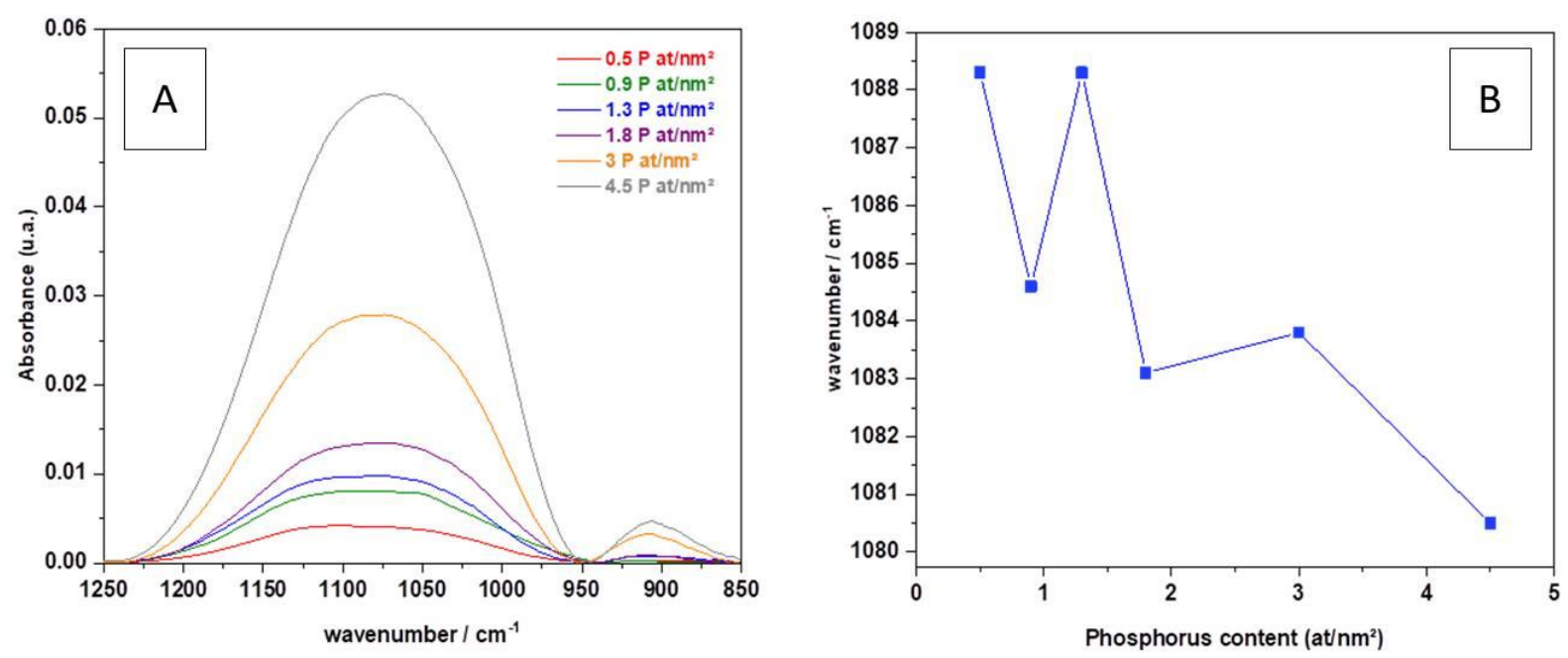

Figure S2 : (A) ATR-IR spectra of dried phosphated alumina at different coverage (from 0.5 to 4.5 at $/ \mathrm{nm}^{2}$ ) subtracted by $\mathrm{Y}^{-}$ $\mathrm{Al}_{2} \mathrm{O}_{3}$ spectra (B) Average location of the ATR-IR band at the different phosphorus coverage (line is used as guidance for the reader). 
The average location of the band (FigureS2.B) has been calculated using the following formula:

$$
\overline{\mathrm{n}}=\frac{\sum_{\mathrm{n}_{i}} \mathrm{n}_{i} \mathrm{~A}\left(\mathrm{n}_{i}\right)}{\sum_{\mathrm{n}_{i}} \mathrm{~A}\left(\mathrm{n}_{i}\right)}
$$

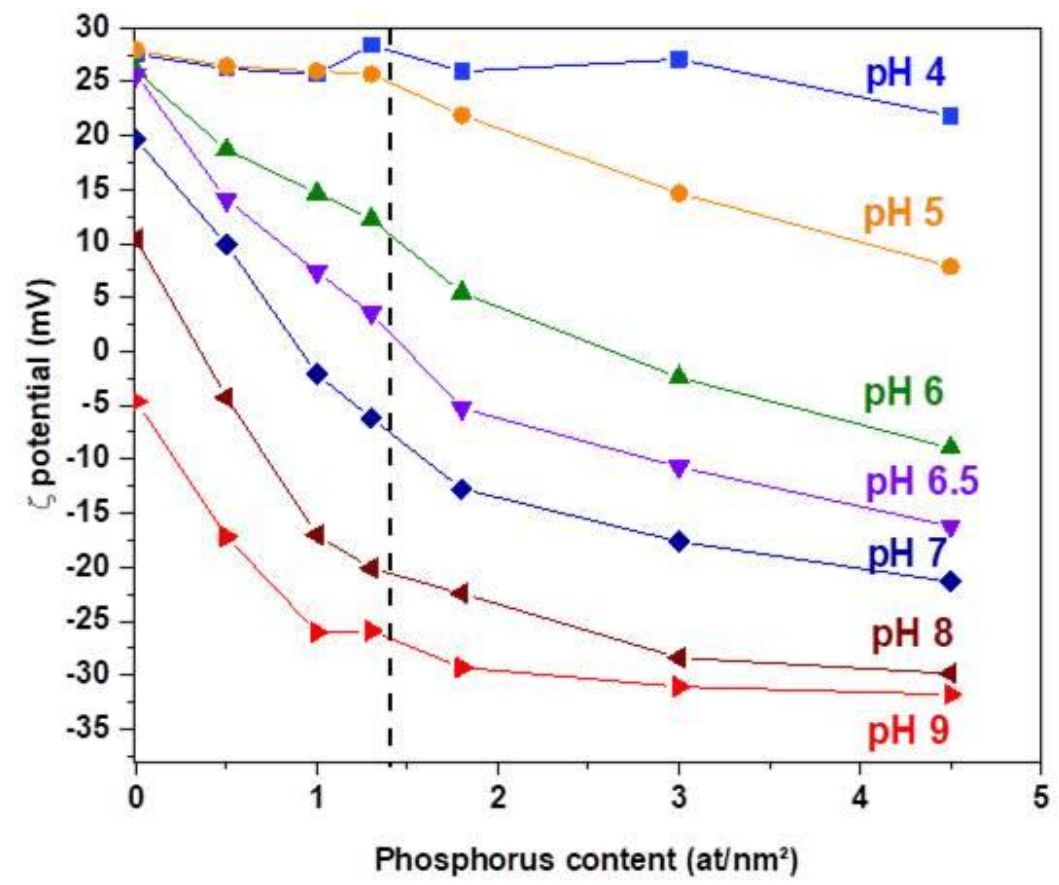

Figure S3 : Evolution of the $\zeta$ potential as function of the phosphorus coverage at different pH (from 4 to 9 ) (lines are used as guidance for the reader).

Table S1 : Characteristics of $\mathrm{y}-\mathrm{Al}_{2} \mathrm{O}_{3}$ Surface $-\mathrm{OH}$ groups at water coverage of 0.17 and $0.18 \mathrm{OH} / \mathrm{nm}^{2}$ for the $(100)$ and (110) orientations ${ }^{1}$.

\begin{tabular}{cccc} 
& & \multicolumn{2}{c}{ Surface density $\left(\mathbf{n m}^{\mathbf{- 2}}\right)$} \\
\cline { 3 - 4 } OH site & Al involved & $\mathbf{( 1 0 0 )}$ & $\mathbf{( 1 1 0 )}$ \\
\hline $\mathrm{H}_{2} \mathrm{O}$ & $\mathrm{Al}_{\mathrm{VI}}$ & 2.17 & 4.48 \\
$\mu_{1}$ & $\mathrm{Al}_{\mathrm{VI}}$ & 2.17 & 1.49 \\
$\mu_{1}$ & $\mathrm{Al}_{\mathrm{IV}}$ & 0 & 1.49 \\
$\mu_{2}$ & $\mathrm{Al}_{\mathrm{VI}}$ and $\mathrm{Al}_{\mathrm{IV}}$ & 1.09 & 2.98 \\
$\mu_{2}$ & Only AlVI & 0 & 1.49 \\
$\mu_{3}$ & Only Al & 1.09 & 1.49
\end{tabular}

Table S2 : Calculation of Protonation Constants Using AIMD Simulations To Determine the Number of $\mathrm{H}$ Bonds around Oxygen Atoms in Hydroxyl Groups $(a+d)$ and the number of $H$ bonds around their respective protons $(p)^{1}$. 


\begin{tabular}{cccc} 
OH site & Al involved & Protonation reaction & Log K \\
\hline$\mu_{1}$ & $\mathrm{Al}_{\mathrm{VI}}$ & $\mu_{1} \mathrm{OH}^{-0.5}+\mathrm{H}^{+} \leftrightarrows \mu_{1} \mathrm{OH}_{2}^{+0.5}$ & 8.16 \\
$\mu_{2}$ & $\mathrm{Al}_{\mathrm{VI}}-\mathrm{Al}_{\mathrm{IV}}$ & $\mu_{2} \mathrm{O}^{-0.75}+\mathrm{H}^{+} \leftrightarrows \mu_{2} \mathrm{OH}^{+0.25}$ & 10.32 \\
$\mu_{3}$ & $\mathrm{Al}_{\mathrm{VI}}$ & $\mu_{3} \mathrm{O}^{-0.5}+\mathrm{H}^{+} \leftrightarrows \mu_{3} \mathrm{OH}^{+0.5}$ & 5.94 \\
\hline \multicolumn{4}{c}{ Surface (110) } \\
\hline$\mu_{1}$ & $\mathrm{Al}_{\mathrm{IV}}$ & $\mu_{1} \mathrm{OH}^{-0.25}+\mathrm{H}^{+} \leftrightarrows \mu_{1} \mathrm{OH}_{2}^{+0.75}$ & 0.12 \\
$\mu_{1}$ & $\mathrm{Al}_{\mathrm{IV}}$ & $\mu_{1} \mathrm{O}^{-1.25}+\mathrm{H}^{+} \leftrightarrows \mu_{1} \mathrm{OH}_{2}^{-0.25}$ & 12.97 \\
$\mu_{1}$ & $\mathrm{Al}_{\mathrm{VI}}$ & $\mu_{1} \mathrm{OH}^{-0.5}+\mathrm{H}^{+} \leftrightarrows \mu_{1} \mathrm{OH}_{2}^{+0.5}$ & 9.16 \\
$\mu_{2}$ & $\mathrm{Al}_{\mathrm{VI}}-\mathrm{Al}_{\mathrm{IV}}$ & $\mu_{2} \mathrm{O}^{-0.75}+\mathrm{H}^{+} \leftrightarrows \mu_{2} \mathrm{OH}^{0.25}$ & 10.45 \\
$\mu_{2}$ & $\mathrm{Al}_{\mathrm{VI}}-\mathrm{Al}_{\mathrm{VI}}$ & $\mu_{2} \mathrm{OH}^{0}+\mathrm{H}^{+} \leftrightarrows \mu_{2} \mathrm{OH}^{+1}$ & 0.29 \\
$\mu_{2}$ & $\mathrm{Al}_{\mathrm{VI}}-\mathrm{Al}_{\mathrm{VI}}$ & $\mu_{2} \mathrm{O}^{-1}+\mathrm{H}^{+} \leftrightarrows \mu_{2} \mathrm{OH}^{0}$ & 13.86 \\
$\mu_{3}$ & $\mathrm{Al}_{\mathrm{VI}}$ & $\mu_{3} \mathrm{O}^{-0.5}+\mathrm{H}^{+} \leftrightarrows \mu_{3} \mathrm{OH}^{+0.5}$ & 4.75
\end{tabular}

1. Corral Valero, M., Prelot, B. \& Lefèvre, G. MUSIC Speciation of $\mathrm{y}-\mathrm{Al}_{2} \mathrm{O}_{3}$ at the Solid Liquid Interface: How DFT Calculations Can Help with Amorphous and Poorly Crystalline Materials. Langmuir 35, 12986-12992 (2019). 